\title{
QUEEN'S
UNIVERSITY
BELFAST
}

\section{The long-term determinants of female HIV infection in Africa: The slave trade, polygyny, and sexual behavior}

Bertocchi , G., \& Dimico, A. (2019). The long-term determinants of female HIV infection in Africa: The slave trade, polygyny, and sexual behavior. Journal of Development Economics, 140, 90-105.

https://doi.org/10.1016/j.jdeveco.2019.05.005

Published in:

Journal of Development Economics

Document Version:

Peer reviewed version

Queen's University Belfast - Research Portal:

Link to publication record in Queen's University Belfast Research Portal

Publisher rights

Copyright 2019, Elsevier.

This work is made available online in accordance with the publisher's policies. Please refer to any applicable terms of use of the publisher.

\section{General rights}

Copyright for the publications made accessible via the Queen's University Belfast Research Portal is retained by the author(s) and / or other copyright owners and it is a condition of accessing these publications that users recognise and abide by the legal requirements associated with these rights.

Take down policy

The Research Portal is Queen's institutional repository that provides access to Queen's research output. Every effort has been made to ensure that content in the Research Portal does not infringe any person's rights, or applicable UK laws. If you discover content in the Research Portal that you believe breaches copyright or violates any law, please contact openaccess@qub.ac.uk. 


\title{
The Long-Term Determinants of Female HIV Infection in Africa: The Slave Trade, Polygyny, and Sexual Behavior*
}

\author{
Graziella Bertocchi† \& Arcangelo Dimico
}

May 2019

\begin{abstract}
We study the long-term determinants of the high rates of female HIV prevalence in sub-Saharan Africa, with a focus on the transatlantic slave trade. Our hypothesis is that the latter contributed to the contemporaneous diffusion of polygyny and associated forms of social and sexual behavior that are conducive to HIV infection. We uncover that an increase in the rate of historical slave density causes a sizeable and robust increase in the rate of HIV prevalence, with a more marked effect among married women, and particularly those that do not live with their husbands. A higher slave density also induces more widespread female infidelity. These patterns are consistent with the hypothesis that higher-rank, non-cohabiting, younger cowives are driven to infidelity by marital dissatisfaction. The resulting risky sexual behavior increases their likelihood to contract and transmit the virus, through the husbands, to their faithful co-wives, with a multiplicative effect among women.
\end{abstract}

JEL Codes: I15, J12, N37, O10.

Keywords: HIV, slave trade, sexual behavior, polygyny.

\footnotetext{
*Acknowledgments: We would like to thank, for helpful comments, the co-editor Nathan Nunn, two anonymous referees, Angus Darlymple-Smith, Omer Moav, and participants at the First CEPR Macroeconomic and Growth Programme Meeting, the Utrecht Conference on Deep Causes of Economic Development, the CSAE Conference 2015 on Economic Development in Africa, the 2015 Royal Economic Society Conference, the Council for European Studies Conference on Women in Society from a Historical Perspective, and seminars at Queen's University Belfast and the Universities of Luxembourg and Oslo. We are grateful to a UNIMORE grant for financial support.

${ }^{\dagger}$ Graziella Bertocchi: University of Modena and Reggio Emilia, CEPR, CHILD, DGI, GLO, and IZA. Address: Dipartimento di Economia Marco Biagi, Viale Berengario, 51, I41121 Modena, Italy, phone: +39 059 2056856, e-mail: graziella.bertocchi@unimore.it, web: http://www.economia.unimore.it/bertocchi_graziella.

${ }^{\ddagger}$ Arcangelo Dimico: Queen’s University Belfast, QUCEH, CHaRMS, GLO, and IZA. Address: Management School, Riddel Hall, 185 Stranmillis Rd, BT9 5EE, Belfast, UK, phone: +44(0)2890974167, e-mail: a.dimico@qub.ac.uk, web: https://sites.google.com/site/arcangelodimico.
} 


\section{Introduction}

HIV/AIDS is one of the most deathly diseases in Africa. In particular, within sub-Saharan Africa, HIV infection is much more common among women, and especially young ones. Violence against women, barriers of access to services, poor education, lack of economic security, and unequal gender norms inducing unsafe sexual behavior are some of the reasons which can explain these peculiarities (UNAIDS, 2016a).

In this paper, we look at the long-term determinants of HIV infection and its gendered pattern with a focus on the potential influence of the transatlantic slave trade. Our hypothesis is that the latter may have permanently shaped social and family structure, as well as sexual behavior, in the direction of more promiscuous mating habits, thus favouring the diffusion of the disease. In particular, we identify women's position within a polygynous union as a key driver of the contagion. Indeed, in present-day sub-Saharan Africa, polygyny has been associated by medical and social science research with sexual habits that are conducive to a higher risk of HIV infection. ${ }^{1}$ Younger co-wives involved in a polygynous marriage may be driven to infidelity because of the unsatisfying nature of their marital relationship. Dissatisfaction can be attributed to the age difference with the husbands, the relationship with older co-wives, and absence of co-residence with the husbands, a frequent living arrangements for younger co-wives. As a result, they may engage in extramarital relationships, a well known risk factor for HIV infection. The effect is reinforced by the fact that, within a polygynous family, men have sexual relationships with multiple women, so that an infected co-wife causes the transmission of the epidemic to the other co-wives, thus amplifying its prevalence among women.

The above mentioned medical literature has established that concurrent partnerships, including those associated with polygyny, represent one of the main risk factors for HIV transmission. At the same time, within the economics literature, a link has been suggested between contemporaneous polygyny in Africa and the unbalanced sex ratios caused by the transatlantic slave trade (Manning, 1990; Dalton and Leung, 2014; Fenske, 2015). Our main contribution is to show the existence of a statistical association running from the slave trade to HIV infection rates. This association is channelled through the social and sexual behavior which is associated with polygyny, including separate living arrangements, especially for younger co-wives, and their relatively more frequent extramarital partnerships. According to our hypothesis, the transatlantic slave trade can then be interpreted as a fundamental risk factor for HIV diffusion.

Figure 1 summarizes the links discussed above. Across sub-Saharan Africa, the transat-

\footnotetext{
${ }^{1}$ See, for example, Halperin and Epstein (2004); Epstein and Morris (2011); WHO (2012); and Poku (2005), as well as the discussion in Sub-section 2.1.
} 
lantic slave trade contributed to the diffusion of contemporaneous polygyny. The associated presence of a pool of potentially unsatisfied young women involved in extramarital relationships induces risky sexual behaviors that in turn represent a vehicle for HIV transmission, with multiplicative effects on women's infection rates.

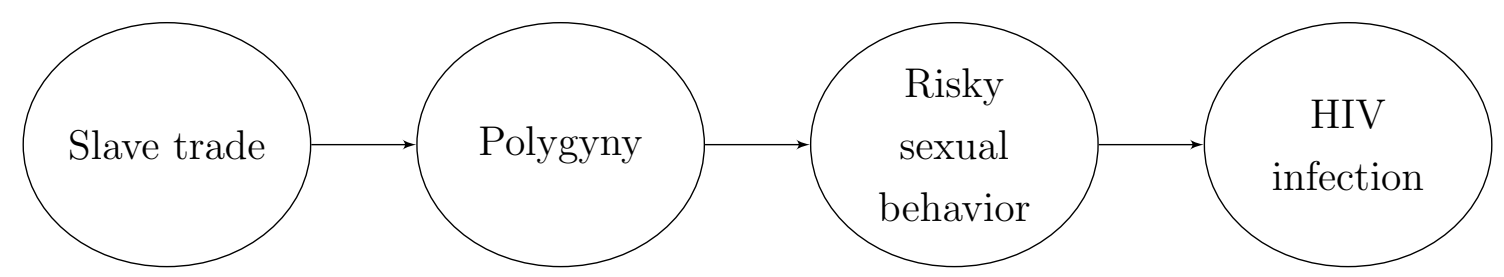

Figure 1: From the Transatlantic Slave Trade to HIV Infection

Based on the intuition emerging from Figure 1, prior to our empirical investigation we generate a simple analytical framework where the diffusion of risky sexual behavior is explained by a set of market clearing conditions for the marriage market that allows the coexistence of polygyny, co-residence patterns involving married individuals who do not share the same residence, and high rates of infidelity for younger women. The resulting promiscuity can be interpreted as a predictor for HIV diffusion and its gendered pattern.

With reference to Figure 1, we organize our empirical investigation as follows. First, we examine the reduced-form relationship between the transatlantic slave trade, a potential fundamental determinant, and HIV infection. Second, we assess whether HIV infection is affected by risky sexual behavior, a candidate proximate determinant. We proceed by investigating the impact of the slave trade on risky sexual behavior and polygyny, as possible channels.

We start by estimating reduced-form OLS regressions where the rate of HIV infection is regressed on the transatlantic slave trade. In order to do so, we combine contemporaneous geo-coded data from the Demographic and Health Surveys (DHS) and the data on the slave trades provided by Nunn and Wantchekon (2011). The results confirm a substantial legacy of the trade: after controlling for cluster-level and individual-level covariates as well as country fixed effects, the rate of HIV prevalence increases by almost half a percentage point for a one standard deviation increase in our measure of slave density, which implies an over 6 percent increase relative to the sample mean. The magnitude of the effect is especially large for women, with an increase reaching more than 7 percent, to be compared to an increase of only about 3 percent for men.

The relationship we uncover between the slave trade and HIV infection is confirmed by a battery of robustness checks. We first show that it is unlikely to be explained away by the influence of unobservable factors. Second, 2SLS estimates rule out potential omitted variables and reverse causality bias. Third, a falsification test using the Indian Ocean 
slave trade corroborates our findings. We also ascertain that our results do not rely on the spatial distribution of the slave trade within Africa. Fourth, another falsification test using the spread of anemia or iodine deficiency rules out an effect of the transatlantic trade on not infectious diseases. Fifth, splitting the sample by age cohorts and gender reveals heterogeneities that support our hypothesis of younger women as drivers of contagion.

Further evidence will then establish that the effect of the slave trade on HIV infection is especially strong for married women who do not share a residence with their partners, for whom the increase in HIV prevalence, for a one standard deviation increase in our measure of slave density, is over 8 percent relative to the sample mean.

Turning to the channels that link the transatlantic slave trade to HIV, we start by showing that indeed risky sexual behavior, as captured by marital infidelity, does correlate with infection, as established by the medical literature. Next, we establish a positive impact of the slave trade on marital infidelity, especially for non-cohabiting women. In turn, more widespread female marital infidelity is also associated with polygyny, consistent with our hypothesis about the role of polygyny in shaping social and sexual behaviors. Lastly, we show that the effect of the slave trade on contemporaneous polygyny depends on age and is positive for the oldest cohort, while its overall effect is negative, albeit small. This heterogenous influence can be explained with the actual decline of its prevalence among younger generations, but also with the evidence we present on underreporting of the practice, a phenomenon which is likely to be especially common among younger women and in the more progressive coastal areas where the transatlantic slave trade was more intense.

To sum up, our results confirm the hypothesis that areas that were more intensively affected by the transatlantic trade and the consequent demographic shock persistently display social and sexual behaviors which are conducive to promiscuity and the spread of the HIV contagion. A crucial channel of transmission is the contemporaneous diffusion of polygyny - a legacy of the unbalanced sex ratio caused by the trade - that is in turn associated with marital dissatisfaction for young, higher-rank co-wives, who tend not share the same roof with their husbands. As a reaction, they are driven to search for extramarital relations. The resulting promiscuity represents a risk factor for HIV infection and, through the husbands, the contagion is then transmitted to the other faithful cowives. Therefore, the transatlantic trade can indeed be identified as a fundamental risk factor for HIV diffusion, whose influence persists across several interrelated dimensions.

An alternative explanation for our findings is that the slave trade may be a driver of HIV infection through a direct influence on contemporaneous norms about family formation and extramarital sexual behavior, other than through polygyny. From the Ethnographic Atlas (Murdock, 1967), we collect additional data on norms of premarital 
sexual behavior for young women and for the prevalence of a bride price in marriage modes. The latter has been associated with more permissive female sexuality, in a context of subsistence farming where wealth depends on women's fertility. However, the absence of compelling evidence confirming a direct influence of the slave trade on these domains reassures us about the relevance of the channels previously identified.

The paper is related to several streams of the literature. The first looks at the economics of HIV in Africa. Most of the contributions are based on randomized field experiments that evaluate the effectiveness of a variety of prevention policies. ${ }^{2}$ Other contributions are based on models of HIV diffusion and its consequences. ${ }^{3}$

Closer to our approach is the stream that has investigated the long-term determinants of HIV prevalence. Mantovanelli (2014) and Cagé and Rueda (2017) analyze the influence of the Christian missions established in Africa during the colonial period. The former finds that exposure to Catholic missions is associated with a decrease in current HIV infection rates, since Catholicism, relative to Protestantism, is positively associated with the adoption of safer forms of sexual behavior, despite its negative impact on the propensity of condom use. The latter evaluates the influence of missions not only on sexual behavior but also on health investment, uncovering conflicting effects on HIV prevalence: through less knowledge about condom use, regions close to historical missions exhibit higher HIV prevalence but, within regions close to missions, proximity to a mission with a health investment is associated with lower HIV prevalence, through safer sexual behavior. Anderson (2018) demonstrates that female HIV rates are higher in common law sub-Saharan African countries, compared to civil law ones, and attributes this difference to the weaker female marital property rights under common law. As a result, women in common law countries have lower bargaining power within the household, are less able to negotiate safe sex practices, and are therefore more vulnerable to HIV. However, this result is shown not to hold for women in polygynous unions. Lowes and Montero (2018) also contribute to this stream since they interpret willingness to consent to a HIV test as a measure of trust in medicine and show that in Central Africa it is negatively affected by greater historical exposure to the French colonial medical campaigns. We view these contributions as complementary to the present one.

Since we interpret the slave trade as a fundamental driver of sexual behavior and of

\footnotetext{
${ }^{2}$ For instance, Auvert et al. (2005) and Gray et al. (2007) focus on male circumcision, Dupas (2011) and de Walque (2007) on information campaigns, Ashraf, Bandiera, and Jack (2014) on condom diffusion, Duflo, Dupas, and Kremer (2015) on sex education in schools.

${ }^{3}$ Young $(2005,2007)$ simulates the impact of AIDS on fertility and human capital. The influence on HIV prevalence of sexual behavior, gender differences in transmission rates, interactions with the marriage market, income shocks, and expectations about future HIV status, is investigated respectively by Oster (2005), Greenwood et al. (2013), Magruder (2011), Burke, Gong, and Jones (2015), and Delavande and Kohler (2016).
} 
the diffusion of sexually transmitted diseases, through its protracted influence on social customs and mating patterns, the present paper is also linked to the literature on persistence of culture, social preferences, and sexual behavior. ${ }^{4}$ While these traits generally tend to be maintained over time, they can also be altered significantly and persistently by external shocks. ${ }^{5}$ Finally, the paper shares features with the literature on long-term development that distinguishes between proximate and fundamental factors of growth, ${ }^{6}$ and with the medical and public health literature that searches for primordial (i.e., deeply rooted) determinants of HIV infection. ${ }^{7}$

The rest of the paper is organized as follows. Section 2 contains background information on the diffusion of the HIV epidemic and the history of the slave trades in Africa. Section 3 introduces a simple marriage market framework. Section 4 describes the data and the empirical strategy. Section 5 presents our main results and a variety of robustness checks. Section 6 investigates the channels of transmission. Section 7 is devoted to a discussion of alternative potential explanations of our findings. In Section 8 we derive our conclusions and policy implications. The Online Appendix contains further information about the data and additional tables with robustness checks.

\section{Background}

\subsection{The HIV Epidemic in Africa}

Despite extraordinary accomplishments in the last 15 years, HIV/AIDS remains an acute problem in the African continent. According to USAIDS (2016b), in 201536.7 million people around the world lived with HIV, while 2.1 million became infected, and 1.1 million died of AIDS. In each dimension, by far the largest shares - 69, 65, and 73 percent respectively - occurred in sub-Saharan Africa. Moreover, in sub-Saharan Africa HIV is much more common among women, who represent 56 percent of the infected, and nearly 68 percent of the infected in the 15-24 year-old age group, with young women having a probability of being infected which is almost eight times larger than for young men.

The medical literature has established that sexual transmission is the main channel

\footnotetext{
${ }^{4}$ See Bisin and Verdier (2001), Alesina and Giuliano (2015), and Giavazzi, Petkov, and Schiantarelli (2014). A closely related investigation of the impact of the slave trade on female labor force participation and gender roles is provided by Teso (2019).

${ }^{5}$ For example, Francis (2008) shows that the outbreak of HIV in the US in the 1990s caused a permanent change in homosexual relationships. Nunn (2012) provides an extensive review of why cultural values and beliefs are important when studying the process of historical economic development.

${ }^{6}$ See Hall and Jones (1999), Acemoglu, Johnson, and Robinson (2002), and Galor and Ashraf (2013).

${ }^{7}$ See Mann and Tarantola (1998).
} 
of HIV diffusion. In particular, promiscuous sexual habits and concurrent partnerships represent particularly high risk factors (Halperin and Epstein, 2004; WHO, 2012). The responsibility for risky sexual behavior has traditionally been attributed to males. It has also been thought that, within serodiscordant couples, men are more likely to be the infected partner. However, recent analysis has challenged such assumptions on the basis of data reporting significant shares of serodiscordant couples where the woman carries the disease (Shelton, 2007; Eyawo et al., 2010). These findings uncover a potential role for female attitudes toward risky sexual behavior and, in particular, concurrent partnerships. Indeed it has been pointed out that not only African men, but also African women, often have more than one concurrent partnership outside the marriage or primary partnership (Halperin and Epstein, 2004). Epidemiological models demonstrate that concurrent partnerships greatly increase the rate of spread of contagion since they raise the probability that uninfected partners have sex to a partner during the acute stage of infection (Watts and May, 1992). The risk of infection increases with the number of partners being involved. Conversely, under serial monogamy, the time gaps between sexual relationships allow that only a single uninfected partner is exposed to an infected one during the acute stages, resulting in a lower risk of transmission (Mah and Halperin, 2010). Multiple concurrent partnerships can be explained on biological and economic grounds, but they are also rooted in culture and history. According to Shelton (2009), only a superficial analysis would attribute them to men's "uncontrollable sexual urges" on the one hand, and to the weak economic and cultural position of women in African societies, on the other. Instead, a prominent explanation is female dissatisfaction with primary relationships, due to lack of communication, sexual discontent, physical abuse, or economic issues.

Again within the medical literature, among other forms of concurrent partnerships a special role is assigned to polygyny. In principle, polygyny is a safe type of concurrency, as long as no member of the household has extramarital partners. Empirically, however, this assumption has been questioned. Using WHO/GPA survey data for six case studies in Africa, an early contribution by Caraël (1995) suggests that polygyny may influence sexual behavior in a manner that is conducive to a higher risk of HIV infection. More recent ecological studies (i.e., studies of risk-modifying factors on HIV infection based on specific populations) have associated polygyny with more extramarital sex and a higher probability of HIV and other sexually transmitted infections. Because the risk to one member of a polygamous family depends upon the behavior of all the others, it has also been pointed out that faithfulness becomes especially important within a polygynous family. These findings are summarized and discussed in Epstein and Morris (2011). Additional related evidence is reported by Kwena et al. (2014), who conduct a survey on 
Kisumu County (Kenya) - an area where polygyny is common - and find that both being in a polygynous union and achieving lower sexual satisfaction within the marriage are associated with an increased likelihood of extramarital partnerships. ${ }^{8}$ While the bulk of the medical literature - including the above reported Caraël (1995), Epstein and Morris (2011), Kwena et al. (2014), and references therein - agrees that polygyny increases HIV infection, an exception is represented by Reniers and Watkins (2010), who find that the spread of HIV is lower where polygyny is common and propose lower coital frequency in polygynous marriages as an explanation. However, they also find that the junior wives of polygynous men are more often HIV positive than wives of monogamous men. Moreover, they control for extramarital relationships, which are the likely channel of transmission within polygamous households, as stressed by Epstein and Stanton (2010) in a critical comment. More generally, the contribution ignores endogeneity issues and the omitted variable bias induced by the limited number of controls being considered.

The social science literature has contributed further qualitative evidence to the above discussion, by highlighting the high social costs associated with polygyny, with an emphasis once again on the fact that it makes it difficult to successfully control the diffusion of sexually transmitted diseases (Caldwell, Orubuloye, and Caldwell, 1992). In particular, consistently with the medical literature, the higher rate of HIV among women is explained by the centrality of men in the household structure, which increases the likelihood of HIV among women exponentially. Furthermore, there are other reported reasons why HIV in polygynous groups is higher among women. In particular, belonging to a polygynous family has been found to be a primary reason of dissatisfaction, especially for young, higher-rank co-wives. While an older co-wife may be sexually neglected, younger ones suffer both from the age difference with the husband and the relationship with previous wives (Weisfeld, Weisfeld, and Dillon, 2018). In fact, older women are usually given authority over younger co-wives and appropriate more resources within the household (Jankowiak, Sudakov, and Wilreker, 2005). Moreover, the wife who bears the first son (typically the first wife) enjoys greater social status within the family and the community. Wife order also matters for resource allocation to the children, with children of older wives often being advantaged in terms of nutrition, survival, and education (Uggla, Gurmu, and Gibson, 2018). Dissatisfaction within the marriage has been viewed as a key driver of marital infidelity, since unhappy co-wives tend to look for extramarital partnerships (Poku, 2005; Ogundipe-Leslie, 1994), thus increasing the probability of HIV infection for the entire household. ${ }^{9}$

\footnotetext{
${ }^{8}$ Evidence from studies on mammals shows that polygyny is normally associated with more sexual activity and a higher rate of sexually transmitted diseases (Ashby and Gupta, 2013).

${ }^{9}$ Female infection is also facilitated by the practice of transactional sex, which is more frequent when poor economic conditions induce young women/wives to accept gifts in exchange of sex with older man
} 
In recent years, despite the fact that polygyny has long been practiced, its legality has been challenged in several sub-Saharan African countries. While it is still legal in some of them (e.g., Cameroon, Gabon, Mali, Senegal, and Zambia), in others it has been outlawed and even criminalized (e.g., Burundi, Cote d'Ivoire, Ethiopia, Guinea, and Rwanda). In other cases, despite the fact that the law prohibits polygyny, customary law still allows men to have several wives (e.g., Lesotho, Liberia, Malawi, Sierra Leone, and Zimbabwe). While the de jure status of polygyny is not reported to have affected systematically its de facto diffusion, the legislation is still actively being reviewed. ${ }^{10}$ Moreover, as a result of social change, there is a tendency toward a decline in the actual practice of polygyny, as documented by Fenske (2015) and Rijpma and Carmichael (2016). This trend has also caught the attention of epidemiologists, who have explored whether it can be a factor in explaining the observed decline in the spread of the HIV virus (Eaton et al., 2014).

To conclude, even though a potential link between polygyny and HIV infection has been suggested by the literature in the medical and social sciences, it has never been explored within the economics literature, using analytical tools that are capable to establish causality. To properly investigate this link, and to connect it with the slave trade as a potential deep determinant of polygyny, represents the contribution of the present paper.

\subsection{The African Slave Trades}

During the transatlantic slave trade, between 1529 and 1850, almost 12.5 million Africans were exported from Africa and forced to undertake the Middle Passage towards the New World (Eltis, 2008). Even though the transatlantic slave trade was by far the most relevant in terms of volumes and duration, another six million slaves were exported within other three slave trades: the trans-Saharan, Red Sea, and Indian Ocean slave trades.

Since slaves were taken in order to provide labor for the plantations, a peculiar characteristic of the transatlantic slave trade was a preference for male slaves, that soon provoked a scarcity of men in the affected areas within Africa. As a consequence, as argued by Fage (1980), Thornton (1980), and Manning (1981), the transatlantic trade caused not only a huge decrease in the rate of growth of the African population, but also a distortive influence on the sex balance. According to Ciment (2007), the estimated population of sub-Saharan Africa in 1850 was at about 50 million, while absent the slave trade it would have been around 100 million, while Thornton (1980) reports that women,

\footnotetext{
(Mbirimtengerenji, 2007; Luke and Kurtz, 2002).

${ }^{10}$ For instance, in 2014 Kenya legalized polygynous civil marriages. In 2003 Namibia passed a bill recognizing polygyny under customary law, but then repealed it in 2009. Uganda outlawed polygyny in 2003, but partially reversed the ban in 2005. For details see the OECD Social Institutions \& Gender Index at www.genderindex.org.
} 
at the peak of the process, outnumbered men by a ratio which could be larger than three women per man. The unbalanced sex ratio provoked a further reduction of the population growth rate and a deep transformation of family structure and sexual behavior. The institution of polygyny was reinforced. Matrilineal lineage faced a serious threat. Co-wife competition, together with a larger wife-husband age gap, further contributed to a decline in population growth (Strassmann, 2000; Lamie, 2007). ${ }^{11}$

The empirical examination of the effects of the African slave trades has been made possible by data collection by Nunn (2008), who constructs estimates of the number of slaves exported from each country in Africa in each century between 1400 and 1900 . The estimates are obtained by combining data on the total number of slaves shipped from all ports and regions of Africa with data on the slaves' ethnic identities. Using these data, Nunn (2008) finds a negative effect of the slave trade in shaping subsequent economic development. For the transatlantic and Indian Ocean slave trades, for which ethnicity data are sufficiently detailed, Nunn and Wantchekon (2011) disaggregate the country-level slave export figures to the ethnicity level and find a negative effect of the slave trade on the contemporaneous level of trust. Figure A1 illustrates the geographical distribution of the number of slaves taken from each ethnicity (defined on the basis of the corresponding land area) during the transatlantic slave trade.

The data provided by Nunn (2008) and Nunn and Wantchekon (2011) have allowed empirical investigations of the impact of the slave trades on other dimensions, including polygyny. ${ }^{12}$ Polygyny was practiced in Africa well before the slave trade. Anthropological and historical research on the African family structure (Boserup, 1970; Goody, 1976; Todd, 1984) attributes the higher incidence of polygyny, if compared to other continents, to agricultural conditions which made female labor valuable. The reliance on females for production provoked a tendency to multiple marriages that was instrumental to sustain reproduction success and lineage subsistence. ${ }^{13}$ As previously mentioned, the diffusion of polygyny was later reinforced because of the transatlantic slave trade, since the associated preference for male slaves led to an unbalanced sex ratio with missing men. In such a context, polygyny ensured no shortage of potential husbands and maximized women's chances of pregnancy.

Building on Thornton (1983), the link between the transatlantic trade and contemporaneous polygyny is empirically investigated by several authors. Dalton and Leung (2014)

\footnotetext{
${ }^{11}$ Historical accounts are provided for instance by Brasio (1958), Labat (1728), and Texeira de Mota (1974).

${ }^{12}$ The economics literature on polygyny includes Becker (1974), Tertilt (2005), Gould, Moav, and Simhon (2008), and Lagerlof (2010).

${ }^{13}$ Jacoby (1995) provides an empirical test of this hypothesis. The importance of ecological factors is confirmed by Lee and Whitbeck (1990) and White and Burton (1988), who find an association between type of agriculture, female labor, and polygyny.
} 
combine the historical data on slave trades from Nunn (2008) and Nunn and Wantchekon (2011) with contemporaneous polygyny data from the female DHS. They show that the higher polygyny rates in Western Africa, if compared to Eastern Africa, can be explained by the transatlantic trade and the consequent scarcity of men. Using a measure of polygyny given by the number of married women over the number of married men (based on United Nations data) Edlund and Ku (2011) argue that polygyny in sub-Saharan Africa is characterized by late but nearly universal marriage for men (general polygyny). Unlike other forms of polygyny involving a large number of wives for high-quality men only, which can be related to wealth inequality, they find that general polygyny is linked to the slave trade. Within a broad analysis of the determinants of African polygyny, Fenske (2015) uses the DHS household-level codification and confirms the existence of a link with the slave trades, even though the latter can only predict the former across broad regions, i.e., West vs East Africa.

The present paper builds on this literature by revisiting the empirical analysis of the impact of the slave trade on polygyny, in light of the hypothesis that the associated social and sexual mores may contribute to our main outcome of interest, namely, the diffusion of HIV infection.

\section{A Marriage Market Framework}

This section presents a simple framework to illustrate the links among the variables that will be the subject of our empirical investigation. The framework consists of a set of market clearing conditions for the marriage market that allow polygyny to coexist with universal marriage, a well-established stylized fact, and at the same time to generate patterns that are consistent with our hypotheses: namely, the simultaneous presence of co-residence patterns involving the existence of married individuals not living together and high rates of infidelity for women. The framework generates an index of promiscuity which can be interpreted as a predictor for HIV diffusion and its higher prevalence for women.

The reference point is the standard market clearing condition for the marriage market proposed by Becker (1973) in a static setting and extended by Neelakantan and Tertilt (2008) to a dynamic environment. We assume the existence of two generations of individuals, young and old, and allow for population growth at a strictly positive rate $n$, such that $M_{y}=(1+n) M_{o}$, where $M_{y}$ and $M_{o}$ denote young and old men, respectively. The same applies to young and old women, $W_{y}$ and $W_{o}$. We assume that the sex ratio is always equal to one, both at birth and at marriage age, thus abstracting from differential mortality rates across gender. For simplicity, we also assume there is no divorce and no 
remarriage. Furthermore, polygyny for men can only occur in old age. It is instructive to derive the market clearing condition separately for young and old men. For young men we have:

$$
(1-\theta) M_{y}=(1-\theta) W_{y}
$$

where $\theta$ is the fraction of individuals who do not marry. Equation (1) states that, under the assumption that polygyny cannot occur in youth for men, the fraction of men who marry in youth is matched with an equal number of young women. For old men we have:

$$
\theta M_{o}+p(1-\theta) M_{o}=\theta W_{y}
$$

Equation (2), where $p$ is the number of additional wives for a currently old man who got previously married in youth, shows that young women that do not get married to young men are matched with old men. To satisfy the assumption of universal marriage, they are first matched to those currently old men who did not get married in youth, i.e., the first component shown on the demand side of the old men marriage market, i.e., on the LHS of (2). The remaining young women marry currently old men who got previously married in youth, thus becoming their second, or higher-rank, wife. As a result of market clearing, all women get married in youth, while a fraction of men get married for the first time in old age. ${ }^{14}$ To be noticed is that women that marry old men $\left(\theta W_{y}\right)$ will be widows in their old age, while there are no widowers in this framework. Combining (1) and (2) and solving for $p$ we obtain:

$$
p=n \theta /(1-\theta)
$$

which implies that polygyny and universal marriage can coexist only with strictly positive population growth and a temporary condition of bachelorhood for some men in their youth. We can now compute the number of young women living in polygynous marriages as second or higher-rank wives, at any time $t$, as:

$$
\theta W_{y}-\theta M_{o}=\theta n W_{y} /(1+n)
$$

Next, we assume that only a fraction $\rho$ of the above live with their husband (while first wives always do), and that only the remaining fraction $(1-\rho)$ are available for extramarital relationships. Assuming, for simplicity, that wives living with their husband are never involved in extramarital relationships, the number of young women in a polygynous marriage but not living with their husband is then given by $(1-\rho) \theta n W_{y} /(1+n)$, which represents the pool of potentially unfaithful co-wives. It increases in $n$ and $\theta$, i.e., with

\footnotetext{
${ }^{14}$ The relationship between polygyny, universal marriage, bachelorhood, and male age at marriage is explored by Edlund and $\mathrm{Ku}(2011)$.
} 
the determinants of polygyny, and decreases with co-residence as captured by $\rho$. A larger pool is in turn a predictor of promiscuity, risky sexual mores, and a more widespread diffusion of the HIV epidemic, particularly for married women. ${ }^{15}$ A further channel, which reinforces this outcome, is the fact that unfaithful women contracting the HIV virus can transmit it to their husband, who can in turn transmit it to other co-wives. The higher the number of co-wives, the stronger the involvement of additional women relative to men.

\section{Data and Empirical Strategy}

The source of the data we use for information on HIV, social and family structure, and sexual behavior is the Demographic and Health Surveys (DHS). The surveys are conducted at a cluster level. A cluster contains about 100 households, out of which a predetermined number of households are interviewed. The core questionnaires in the DHS surveys include a household questionnaire, a women's questionnaire, and a men's questionnaire. Within each cluster, the number of households selected for male interviews is usually considerably lower than for female. Additionally, the biomarker questionnaire reports information on a HIV blood test. ${ }^{16}$ Respondents are between age 15 and 59. ${ }^{17}$

In order to select the countries to be included in our sample we adopt the following criteria. First, to match DHS data with the data on the slave trades, which are available at an ethnic level from Nunn and Wantchekon (2011), we need to spatially map clusters within each ethnicity (as described by Murdock, 1959). Therefore, we only consider countries for which Global Positioning System (GPS) records are available. Among countries for which we have GPS data, we then choose those for which we also have HIV data from the HIV dataset of the DHS. To obtain a homogenous sample, we only consider countries for which both the male and female datasets are available. ${ }^{18}$

The 20 countries in our sample are Burkina Faso, Burundi, Cameroon, Congo Democratic Republic, Cote d'Ivoire, Ethiopia, Gabon, Ghana, Guinea, Kenya, Lesotho, Liberia,

\footnotetext{
${ }^{15}$ Greenwood et al. (2013) develop a model where individuals can choose between married and single life, and singles can choose between abstinence and sex, with or without a condom. Under the assumption that married individuals are faithful to their partners, and abstracting from polygyny, they find that marriage can help to abate HIV.

${ }^{16}$ Information on the HIV testing procedure is available at dhsprogram.com/topics/HIV-Corner/hivprev/index.cfm.

${ }^{17}$ See dhsprogram.com/What-We-Do/Survey-Types/DHS-Questionnaires.cfm. For further details on the DHS see also ICF International (2012).

${ }^{18}$ Since the HIV dataset provides data on infection rates based on blood tests, it is preferable to the survey data on attitudes toward HIV, which are provided by the AIDS Indicator Survey (AIS) with the goal of monitoring the effectiveness of HIV/AIDS programs. Moreover, the AIS only includes the household and the women's questionnaire.
} 
Malawi, Mali, Rwanda, Senegal, Sierra Leone, Swaziland, Zambia, and Zimbabwe. In all cases the most recent survey is chosen. We start with the VI wave and then, if no data is available for the VI wave, we turn to the V or IV waves. The countries, waves, and years of the surveys included in the final sample are reported in Table A1. ${ }^{19}$

For the countries in our sample, first we spatially merge DHS clusters with ethnicities, as from the classification in Murdock (1959), by mapping GPS point coordinates for each cluster onto ethnicities. ${ }^{20}$ As a result, clusters which fall within the same ethnicity will display a similar exposure to the slave trades. Next, in order to obtain control variables at a cluster level, we use a Voronoi partition such that a country with $n$ clusters is partitioned into $n$ regions, whereas each region contains exactly one cluster and is closer to its generating point than any other region. The average area for a cluster obtained with this transformation is close to 0.09 degrees (i.e., 10 square kilometers at the equator), with a standard deviation of 0.27 (i.e., close to 30 square kilometers). Clusters and the corresponding point coordinates are illustrated in Figure A2.

By merging the HIV dataset with the household dataset and the male and female datasets, we obtain a sample of 243,707 observations over 8,219 clusters and 343 ethnic groups. This sample is smaller than the household and the sum of the male and female samples, since the HIV sample is significantly smaller. The fact that the blood test is not compulsory may produce selection in the sample, but the DHS program reports that the average response rate, for those who are eligible for the test, is extremely high and that a comparison between the characteristics of those who agree to be tested and those who refuse shows minimal bias. ${ }^{21}$ Moreover, it is reasonable to expect that any selection will cause a downward bias, since infected individuals should be less keen to be tested. ${ }^{22}$ As a result, if HIV infection is positively affected by the transatlantic slave trade, we should expect more underreporting in regions exposed to it. In order to check this hypothesis, we test the potential effect of the slave trade on the probability of underreporting HIV infection, which in practice amounts to a refusal to consent to the blood test. ${ }^{23}$ Control-

\footnotetext{
${ }^{19}$ The distribution of the population in the DHS is not entirely representative of the country population, with (rural) regions with a smaller population being oversampled and regions with a larger population being undersampled, which results in biased estimates. For this reason, we use sample weights, so that estimates will be weighted by probability sampling weights provided in each sample.

${ }^{20}$ While we use location to link the slave trade to contemporary outcomes, another option would have been to use self-reported ethnicity or mother tongue. However, for the country-wave combinations in our sample, neither ethnicity nor mother tongue is reported for several countries (Burundi, Liberia, Lesotho, Rwanda, Swaziland, and Zimbabwe). For other countries, the region of residence is reported instead of the ethnicity. Furthermore, for a few countries the DHS report the cultural cluster and not the ethnic group.

${ }^{21}$ See dhsprogram.com/topics/HIV-Corner/hiv-prev/index.cfm.

${ }^{22}$ This is confirmed by Mishra et al. (2006), who find that the rate of HIV infection among individuals not tested for HIV is systematically larger than the rate among those not tested.

${ }^{23}$ All individuals in our dataset are eligible for the blood test. Therefore, the only ones for whom the
} 
ling for country fixed effects, we find a positive effect of the slave trade on the probability of underreporting (namely, a one standard deviation increase in the intensity of our slave trade measure leads to an almost 7 percent increase in the probability). While underreporting may also be an issue for infidelity, again we should expect it to induce, if anything, a downward bias, since it is more likely to happen where infidelity is stigmatized (i.e., where HIV diffusion is higher).

Within their dataset on the slave trades, Nunn and Wantchekon (2011) provide figures on the total transatlantic slave trade for each ethnic group in Murdock (1959). They also provide data on the size of the land area corresponding to each ethnic group. We employ a measure of slave trade density which is equal to the number of transatlantic slaves divided by the the area of land inhabited by the ethnic group during the nineteenth century. The same measure is employed by Nunn and Wantchekon (2011) in most of their analysis.

In order to investigate the long-term impact of the slave trade we estimate variants of the following empirical model:

$$
Y_{i, j, c}=\sum_{c=1} \pi_{C} \cdot 1_{C i=c}+\beta_{1} \text { SlaveTrade }_{j, c}+\beta_{2} Z_{j, c}^{1}+\beta_{3} Z_{i, j, c}^{2}+v_{i, j, c}
$$

where $Y_{i, j, c}$ represents an outcome variable for individual $i$ in DHS cluster $j$ and country $C$. The main outcome variable is HIV prevalence, which is measured using a dummy variable taking value one when an individual is positive to the blood test for HIV, and zero otherwise. To investigate transmission channels we will also use as dependent variables proxies for social and sexual characteristics such as polygyny, infidelity, and co-residence. The main regressor in Equation (5) is the transatlantic slave trade (i.e., slave exports normalized by land area). Since the distribution of the variable is skewed, we enter it in natural logarithmic form and, to retain observations equal to zero, before taking the logarithmic transformation we add 0.01 to each value. We include country fixed effects $\left(\sum_{c=1} \pi_{C} \cdot 1_{C i=c}\right)$ in order to control for institutional and policy factors (e.g., health programs). The model also includes a set of cluster-level historical, geographical, and economic controls denoted by $Z_{j, c}^{1}$, that comprises Regional GDP in 2000, Population Density in 2000, Population Density in 1800, Rugged Terrain, Mean Elevation, Water Basins, Rainfall, Temperature, Soil PH, Soil Nutrients Availability, Growing Season, Colonial Routes, Colonial Railways, and Christian Missions. ${ }^{24}$ The vector $Z_{i, j, c}^{2}$ denotes a

results of the test are missing are those who refuse to consent to the test. We restrict the analysis to the women's dataset, for which data on consent to the test is available for a much larger sample (the household dataset includes far fewer observations and for the men's dataset the variable is present only for Zimbabwe). We code a dummy variable which is equal to one if the woman refuses to consent to the test, and zero otherwise. Over the women's sample, the consent rate is 94 percent.

${ }^{24}$ Regional GDP in 2000 is measured in terms of lights at night data from the National Geophysical Data Center (Ghosh et al., 2010). The source for Colonial Routes and Railways is Nunn and Wantchekon 
number of individual and household controls taken from the DHS (i.e., Year of the Survey, Age, Sex, Marital Status, Education, Religion, Employment, Wealth, Relationship to the Head, Age of the Household Head, Sex of the Household Head, and Number of Household Members). ${ }^{25}$ Lastly, $v_{i, j, c}$ is the error term.

We will start by clustering standard errors at a DHS cluster level, to account for the DHS complex sampling design and potential design effects. Then we will also cluster them at a coarser ethnicity level, to capture the fact that the assignment is constant at the ethnicity level, causing serial correlation within groups. Furthermore, because of limitations related to clustering (see Barrios et al., 2012) and issues with high leverage observations (see Young, 2019), we will show p-values obtained from randomized inference, in order to test the sharp null of no effect (Fisher, 1935). We will first randomize at an individual level and then at an ethnicity level, to capture the fact that treatment assignment changes at an ethnicity level. Under both randomization specifications, standard errors will be clustered at an ethnicity level.

Description and sources for each variable are detailed in the Appendix (Table A2). Table A3 reports summary statistics. The average rate of HIV infection in our sample is close to 6 . The Number of Wives variable reflects the number of wives (if the individual being interviewed is a man), or co-wives (if the individual is a woman). ${ }^{26}$ The average number of wives per husband in the sample is 1.25 . We also introduce a binary measure of polygyny that takes value one when the number of wives (if the individual being interviewed is a man) or co-wives (if the individual is a woman) is respectively greater than one or zero; otherwise, the variable takes value zero. Almost 19 percent of the respondents report polygyny. Infidelity is captured by a dummy variable that is equal to one if the number of sexual partners (spouses excluded) within the last 12 months is larger than zero, and zero otherwise. Considering female and male infidelity separately, 13 and 26 percent of (married) women and men, respectively, report to have been unfaithful. Average age is between 25 and 30 .

Splitting the sample between the respondents belonging to a polygynous and a monogamous union in Tables A4 and A5, we observe that for the former the rate of HIV infection is lower, while no co-residence, female infidelity, and the Islamic religion affiliation are more common, average wealth is lower, and the intensity of the transatlantic slave trade is higher.

In order to compare observables across clusters with a different intensity of the transat(2011), for Christian missions is Nunn (2010).

${ }^{25}$ While some of the contemporary covariates may represent "bad controls" because they may be endogenous, we still include them to assess whether the slave trade still matters after conditioning on the underlying transmission channels.

${ }^{26}$ To be noticed is that these questions are asked only to married men and women. 
lantic trade, we construct a dummy variable that is equal to one if in the cluster the number of slaves (i.e., the treatment) is larger than zero, and zero otherwise, and we regress on this dummy variables capturing the current and historical level of development (namely, Regional GDP in 2000, Population Density in 2000, Population Density in 1800, Colonial Routes, Colonial Railways, and Distance from the Coast) and individual and household characteristics (namely, Sex and Age for the Head and the Member of the Household, Education, Wealth, and Polygyny). The results are reported in Table A6. For the first set of variables, we cluster errors at an ethnicity level and find that there are no noteworthy differences between the treated and the untreated sample except, as expected, for distance from the coast. ${ }^{27}$ For the second set of variables, we cluster errors at a DHS cluster and at an ethnicity level and do find some differences. For example, in the slave clusters the household head is more likely to be male and older. However, these differences are likely to be the result of polygyny, which is also consistently more diffused in the treated sample. On the other hand, no noteworthy difference emerges for wealth, which excludes a potential selection into polygyny depending on this factor.

\section{Main Results}

\subsection{The Slave Trade and Female HIV Infection}

We begin by estimating the relationship between the transatlantic trade and HIV infection in a parsimonious specification that only includes country fixed effects, for the full sample and then by gender (Table 1, Models 1-3). In Models 4-6 we present an extended specification including all controls. ${ }^{28}$

The legacy of the slave trade is substantial: with reference to the full sample in Model 4, a one standard deviation increase in the intensity of our slave trade measure (1.603 in the estimated sample) leads to an increase in the rate of HIV prevalence by 0.47 percentage points, or by 6.1 percent relative to the sample mean of the dependent variable among individuals whose ethnic group was unaffected by the transatlantic slave trade $(0.0774$ in the estimated sample). ${ }^{29}$ As a thought experiment, we can therefore conjecture that, for a one standard deviation smaller slave density, we would observe today 1.5 million fewer

\footnotetext{
${ }^{27}$ The negative effect of the slave trade on economic development in Africa found by Nunn (2008) can be reconciled with our findings regarding Regional GDP, since he uses a cross-country approach while we look at the within-countries effect.

${ }^{28}$ In Table 1, as well as in Tables 2, 3, 5, and 7, where the slave trade is the treatment, standard errors clustered at the DHS cluster and ethnicity level are presented in parentheses and square brackets, respectively, while randomized-inference $p$-values at the individual and ethnicity level are reported in curly and angle brackets, respectively.

${ }^{29}$ The coefficient would be identical or larger if we were to drop observations in the top first or third percentile of the distribution of the share of slaves. Results are omitted for brevity.
} 
Table 1: HIV and the Slave Trade

\begin{tabular}{|c|c|c|c|c|c|c|}
\hline & \multicolumn{6}{|c|}{ HIV } \\
\hline & (1) & $(2)$ & (3) & (4) & $(5)$ & (6) \\
\hline \multirow[t]{5}{*}{ Slave Trade } & 0.00217 & 0.00289 & 0.00136 & 0.00290 & 0.00426 & 0.00148 \\
\hline & $(0.000462)$ & $(0.000598)$ & $(0.000493)$ & $(0.000810)$ & $(0.00107)$ & $(0.000883$ \\
\hline & {$[0.00141]$} & {$[0.00170]$} & {$[0.00112]$} & {$[0.00236]$} & {$[0.00277]$} & {$[0.00195]$} \\
\hline & $\{0.000\}$ & $\{0.000\}$ & $\{0.000\}$ & $\{0.000\}$ & $\{0.000\}$ & $\{0.000\}$ \\
\hline & $\langle 0.159\rangle$ & $\langle 0.115\rangle$ & $\langle 0.286\rangle$ & $\langle 0.098\rangle$ & $\langle 0.044\rangle$ & $\langle 0.343\rangle$ \\
\hline Controls & No & No & No & Yes & Yes & Yes \\
\hline Country FE & Yes & Yes & Yes & Yes & Yes & Yes \\
\hline Adj. R-sq. & 0.074 & 0.086 & 0.061 & 0.122 & 0.137 & 0.099 \\
\hline Observations & 221346 & 119286 & 102060 & 178605 & 95604 & 83001 \\
\hline DHS Clusters & 8219 & 8216 & 8216 & 6750 & 6744 & 6746 \\
\hline Ethnicities & 343 & 343 & 343 & 308 & 308 & 308 \\
\hline Oster Test & -0.286 & -0.352 & -0.290 & -0.578 & -0.642 & -0.446 \\
\hline Sample & Full & Women & Men & Full & Women & Men \\
\hline
\end{tabular}

Note: OLS estimates. HIV is a dummy variable for testing positive to HIV. Slave Trade is the natural log of 0.01 plus transatlantic slave exports normalized by ethnic land area. Clustered robust standard errors at a DHS cluster level in parentheses. Clustered robust standard errors at an ethnicity level in square brackets. Randomization inference based $p$ values with individual level treatment assignment and clustering at an ethnicity level in curly brackets. Randomization inference based $p$-values with ethnicity level treatment assignment and clustering at an ethnicity level in angle brackets. In Models 4-6 the controls include: Regional GDP 2000, Population Density 2000, Population Density 1800, Rugged Terrain, Mean Elevation, Water Basins, Rainfall, Temperature, Soil PH, Soil Nutrients Availability, Growing Season, Colonial Routes, Colonial Railways, Christian Missions, Year of the Survey, Age, Sex, Marital Status, Education, Religion, Employment, Wealth, Relationship to the Head, Age of the Household Head, Sex of the Household Head, and Number of Household Members. Sex is dropped from Models 2, 3, 5 and 6.

infected people in sub-Saharan Africa, that is, 23.8 million rather than 25.3 million as estimated by USAIDS (2016b). ${ }^{30}$

Splitting the sample along the gender dimension demonstrates that the effect of the transatlantic trade is stronger for the female sample (Model 5), with a larger coefficient than for men (Model 6). In fact, a one standard deviation (1.604) increase in the intensity of the trade increases the female HIV prevalence rate by up to 0.7 percentage points, a 7.4 percent increase relative to the sample mean (0.0926), more than twice the increase we obtain for men, which is limited to 3.3 percent. ${ }^{31}$

It is instructive to report how the dependent variable is also affected by other covariates (see Table A7). For the extended specification over the full sample in Model 4, we detect a negative effect for colonial routes, a positive one for colonial railways, and a

\footnotetext{
${ }^{30}$ As mentioned in the previous section, HIV data are likely to be affected by selection, since infected individuals are less keen to take the test. However, since selection tends to be more severe in areas with a higher prevalence of HIV, this will tend to underestimate the effect of the trade on HIV.

${ }^{31}$ As a comparison, Teso (2019) finds that a similar variation in slave intensity causes an increase by 4.5 percent in female labor force participation.
} 
negative but negligible one for Christian missions. ${ }^{32}$ Turning to the influence of individual characteristics, the probability of infection is higher for female and married respondents, increases with age and wealth, and decreases with education. The relative effect of the ten different religious denominations we include is always very small. ${ }^{33}$ The age of the household head, that we insert together with the age of the respondent in order to control for age differences between husbands and wives, has a positive but negligible effect. In the subsequent discussion, we shall refer to the controls included in Models 4-6, unless otherwise specified, as a benchmark. ${ }^{34}$

\subsection{Robustness Checks}

In this sub-section, we undertake a number of robustness checks in order to validate our findings regarding the link between the transatlantic slave trade and HIV prevalence, especially for women, as highlighted in Table 1.

Selection on observables Our estimates may still be biased by unobservable factors correlated with selection into the slave trade and subsequent HIV prevalence. In order to gauge this possibility, we rely on a method provided by Oster (2017) that, building on Altonji, Elder, and Taber (2005), assesses how large the bias due to unobservables should be, in comparison to that due to observables, in order to explain away the estimated effect. The ratio between the two components of the bias is denoted as $\delta$. Table 1 reports results for the values of $\delta$ that ensure a zero value for $\beta_{1} \cdot{ }^{35}$ For all models, the value of $\delta$ is reassuringly negative, which denotes a negative correlation between observables and unobservables and implies that the coefficient increases when controls are added to the model. ${ }^{36}$

Instrumenting for the slave trade OLS estimates may be biased because of omitted variables and reverse causality. For example, a higher rate of HIV could induce people

\footnotetext{
${ }^{32}$ Mantovanelli (2014) finds that Catholic missions reduce HIV prevalence, while Cagé and Rueda (2017) find that distance to a Protestant mission is associated with a decrease in HIV prevalence. It should be stressed that each contribution, including the present one, is based on different data sources, variable codifications, and samples of countries.

${ }^{33}$ Anderson (2018) finds that HIV rates are higher in common law countries, but only for non-Muslim (and non-polygynous) women.

${ }^{34}$ Appendix Table A8 presents an unweighted OLS version of Table 1 with Conley (1999) spatial HAC standard errors, for three alternative windows of 50, 150, and $250 \mathrm{~km}$.

${ }^{35}$ As suggested by Oster (2017), we select a value for $R^{2} \max$ (i.e., the value of the $R^{2}$ when controlling for both observables and unobservables) equal to 1.3 times the value of the $R^{2}$ for the fully controlled model.

${ }^{36}$ As explained by Fenske (2015), Satyanath, Voigtlander, and Voth (2017), and Hoffman, Mitchell, and Tadelis (2018), a ratio less than zero suggests that the true, bias-adjusted coefficients are larger than the estimated ones and that in the worst case scenario the effect would be further away from zero (i.e., estimated results are downward biased) if additional controls were included.
} 
to be more selective in their choice of partners (and/or engage in more protected sex), causing a downward bias of the effect of the transatlantic trade given that changes in this behavior are likely to be larger in societies exposed to the shock. Thus, we estimate 2SLS models using distance from the coast as an instrument for the transatlantic trade. According to Nunn and Wantchekon (2011), the exogeneity of distance from the coast is the result of the unique history of sub-Saharan Africa since, before the transatlantic slave trade, Africans were not engaged in overseas external trade. As a result, distance from the coast should be independent on measures of development that may in turn affect trust - their focal variable - other than through the slave trade. A similar argument can be applied to our own focal variable, namely, contemporaneous HIV infection rates.

In our context, a potential issue when using distance from the coast as an instrument is related to HIV underreporting, since in coastal areas individuals tend to be more progressive and therefore might be less reluctant to reveal to be infected. If this were the case, the instrument would be likely associated with omitted characteristics which can determine a sort of selection into the sample. Thus, we preliminarily test the potential effect of distance from the coast on the probability of underreporting HIV infection. Since distance from the coast exerts a zero effect on the probability to consent (Table A9, Model $1)$, we can rule out any selection correlated with the instrument.

Table A10 in the Appendix presents 2SLS estimates of the effect of the transatlantic trade on HIV that largely confirm the OLS, with a higher spread of the epidemic among women (Model 2), for whom the coefficient on the slave trade becomes over 50 percent larger than in the OLS estimates, with an implied proportional percent increase in the probability of infection. ${ }^{37}$ On the other hand, the effect on men (Model 3) is attenuated if compared to OLS, thus widening the gender differential.

Geographical heterogeneity So far we have focused on the transatlantic slave trade, since it is reported to be the one that most significantly affected historical sex ratios and, through that channel, provoked a scarcity of men and reinforced the institution of polygyny. However, the Indian Ocean trade was also characterized by a gender preference, albeit reversed, since in this case female slaves were in greater demand. This dissimilarity allows us to perform a falsification test. ${ }^{38}$ Model 1 of Table A11 shows that the Indian Ocean slave trade indeed exerts a marginal impact if compared to the transatlantic one

\footnotetext{
${ }^{37}$ First-stage statistics show that distance from the coast represents a relevant instrument for the trade, with the former being negatively associated with the latter. Even though weak identification tests should be taken with caution in the presence of heteroskedasticity, they tend to reject the null that the instrument and the endogenous variable are weakly correlated. This is confirmed by the F test of excluded instruments, which shows values above 10 .

${ }^{38}$ Teso (2019) also applies a similar placebo in order to gauge the differential impact of the slave trades on gender roles.
} 
(the former yields a 1.3 percent increase of infection, against a 5.2 percent for the latter). ${ }^{39}$ This points to a crucial role for the preference for males and the resulting scarcity of men, which were uniquely associated with the transatlantic trade. ${ }^{40}$

Even though the transatlantic slave trade was not confined to the Western coast of Africa, since slaves were taken also from the Central and Eastern areas of the continent, the influence of its spatial distribution on our results may be a concern. To assure that they do not depend on a broad comparison of the countries affected by the slave trade and the countries that were not, in Table A11 we perform two robustness checks. First, in Models 2 and 3, we add longitude to the controls. The estimates remain very close to those in Table 1 (Models 4 and 5), confirming a similar magnitude for the effect of the trade on HIV infection for the full sample and the female sample (i.e., a 5.2 and 7.5 percent increase, respectively). ${ }^{41}$ Next, we restrict the sample to the countries that were affected by the transatlantic trade. ${ }^{42}$ The estimates show a reinforced effect of the trade, which reaches 19.4 percent for the full sample in Model 4, and 23.2 percent for the female sample in Model 5, while the impact remains smaller - at 13 percent - for the (unreported) male sample. ${ }^{43}$ Thus, our findings do not rely on a comparison between those countries that were affected by the transatlantic trade and those that were not, since an even larger impact emerges within the former. ${ }^{44}$

Not sexually transmitted diseases HIV is a highly infectious, largely sexually transmitted disease. Using DHS data on hemoglobin markers and the resulting level of anemia - only available for female respondents - in Table A12, Model 1, we perform another falsification test by estimating the effect of the transatlantic trade on anemia, which is

\footnotetext{
${ }^{39}$ The effect of the Indian Ocean trade is similarly small even if we exclude the transatlantic trade as a control.

${ }^{40}$ The other two minor trades, across the Red Sea and the Saharan desert, were also associated with a preference for females. However, we cannot extend our test to them since, as explained by Nunn and Wantchekon (2011), the available ethnicity data do not allow to construct reliable estimates of the number of slaves taken from each ethnicity.

${ }^{41}$ Consistently with Table 1 (Model 6), again the effect for males is less than half at 3.5 percent. The regression for the male sample is omitted for brevity.

${ }^{42}$ The resulting sub-sample includes Burkina Faso, Cameroon, Cote d'Ivoire, Democratic Republic of Congo, Gabon, Ghana, Guinea, Liberia, Malawi, Mali, Senegal, and Sierra Leone. Zambia and Zimbabwe, which had a negligible number of slaves being taken, are not included.

${ }^{43}$ Analogous concerns are raised in the working paper version of Fenske (2015) with reference to the relationship between the slave trade and polygyny, which he shows not to hold to the inclusion of longitude and to the exclusion of East Africa.

${ }^{44}$ Lowes and Montero (2018) show that the medical campaigns organized by the French colonial governments in Central Africa reduce current trust in medicine, as measured by the willingness to consent to the HIV test. A further robustness check shows that our results are robust to the exclusion of the Central Africa countries investigated by Lowes and Montero (2018) and included in our sample (i.e., Cameroon and Gabon). This rules out a potential bias due to underreporting in these countries. Results are omitted for brevity.
} 
not sexually transmitted. ${ }^{45}$ We find that, unlike for HIV, the intensity of the trade is associated with a modest increase (1.5 percent) in the prevalence of female anemia, corroborating the hypothesis that sexual behavior is the driver of our results concerning HIV. The reasons why we select anemia for this test rest on its relevance, given the association between anemia and malaria, another vast-scale health problem in Africa, and also on comparison purposes with Cagé and Rueda (2017), Anderson (2018), and Lowes and Montero (2018), who perform similar falsification tests. In Model 2 we show that the same conclusions hold for a predictor of iodine deficiency (with a negative, close to nil percent increase in its diffusion). ${ }^{46}$

Cohort effects In order to investigate heterogeneities across cohorts, in Table A13 we re-estimate the regression of HIV infection on the transatlantic trade by age cohort, by confining the estimate to respondents aged 15-19, 20-29, 30-44, and 45-59. ${ }^{47}$ The influence of the trade varies with age in a non linear fashion, a pattern that can only in part be explained by the fact that the dependent variable captures the prevalence of the disease (i.e., the stock), rather than its incidence (i.e., the flow of newly infected), given that the oldest have been exposed to the risk of infection for longer. Once again, more information is revealed when we split the samples also by gender (Table A14). For the first three cohorts, the effect of the trade on infection is largely driven by females, with almost no effect for men, while for the oldest cohort the effect is much smaller (3 percent) for the women, who are the least likely to be sexually active, than for the men (10.5 percent), who are the most likely to have higher-rank wives.

\subsection{Marital Status and Residential Patterns}

Having established a robust influence of the slave trade on HIV infection, especially for women, in Table 2 (Models 1 and 2) we also split the sample along the marital status dimension. If compared to the 6.1 percent increase in the rate of HIV prevalence we found for the full sample (Table 1, Model 4), now for (currently) married individuals the effect of the slave trade on the probability of infection reaches 6.4 percent, while it is nearly nil for unmarried (i.e., never married) ones. The next two models show that for married women the increase is 6.3 percent, for married men only 5.4 percent. Finally, the last two models show that for unmarried women the effect reduces to 5.4 percent, while it

\footnotetext{
${ }^{45}$ We measure the severity of the illness with a dummy variable taking value one when an individual is diagnosed with either mild, moderate, or severe anemia, and zero otherwise.

${ }^{46}$ Since fortification of salt with iodine, an important micronutrient for physical and mental development, is the most common method of preventing iodine deficiency, the DHS tests household salt samples for iodine levels. Our dependent variable is a dummy variable taking value one when the test reports more than 15 parts of iodine per million of salt (15 ppm), and zero otherwise.

${ }^{47}$ The age of the respondent is dropped from these specifications.
} 


\begin{tabular}{|c|c|c|c|c|c|c|}
\hline & \multicolumn{6}{|c|}{ HIV } \\
\hline & (1) & $(2)$ & (3) & (4) & $(5)$ & (6) \\
\hline \multirow[t]{5}{*}{ Slave Trade } & 0.00298 & 0.000276 & 0.00332 & 0.00251 & 0.00224 & -0.00120 \\
\hline & $(0.00113)$ & $(0.000724)$ & $(0.00130)$ & $(0.00135)$ & $(0.00131)$ & $(0.000785)$ \\
\hline & {$[0.00289]$} & {$[0.000746]$} & {$[0.00315]$} & {$[0.00263]$} & {$[0.000840]$} & {$[0.000848]$} \\
\hline & $\{0.000\}$ & $\{0.601\}$ & $\{0.000\}$ & $\{0.003\}$ & $\{0.019\}$ & $\{0.054\}$ \\
\hline & $\langle 0.169\rangle$ & $\langle 0.692\rangle$ & $\langle 0.41\rangle$ & $\langle 0.264\rangle$ & $\langle 0.036\rangle$ & $\langle 0.086\rangle$ \\
\hline Controls & Yes & Yes & Yes & Yes & Yes & Yes \\
\hline Country FE & Yes & Yes & Yes & Yes & Yes & Yes \\
\hline Adj. R-sq. & 0.105 & 0.110 & 0.103 & 0.110 & 0.154 & 0.065 \\
\hline Observations & 103396 & 63524 & 58606 & 44790 & 28147 & 35377 \\
\hline DHS Clusters & 6749 & 6633 & 6731 & 6684 & 5991 & 6398 \\
\hline Ethnicities & 308 & 307 & 308 & 308 & 301 & 306 \\
\hline \multirow[t]{2}{*}{ Sample } & Married & Unmarried & Married & Married & Unmarried & Unmarried \\
\hline & & & Women & Men & Women & Men \\
\hline
\end{tabular}

Note: OLS estimates. HIV is a dummy variable for testing positive to HIV. Slave Trade is the natural log of 0.01 plus transatlantic slave exports normalized by ethnic land area. Clustered robust standard errors at a DHS cluster level in parentheses. Clustered robust standard errors at an ethnicity level in square brackets. Randomization inference based $p$-values with individual level treatment assignment and clustering at an ethnicity level in curly brackets. Randomization inference based $p$-values with ethnicity level treatment assignment and clustering at an ethnicity level in angle brackets. The controls include: Regional GDP 2000, Population Density 2000, Population Density 1800, Rugged Terrain, Mean Elevation, Water Basins, Rainfall, Temperature, Soil PH, Soil Nutrients Availability, Growing Season, Colonial Routes, Colonial Railways, Christian Missions, Year of the Survey, Age, Sex, Marital Status, Education, Religion, Employment, Wealth, Relationship to the Head, Age of the Household Head, Sex of the Household Head, and Number of Household Members. Sex is dropped from Models 2, 3, 5 and 6. Sex is dropped from Models 3-6.

turns negative for unmarried men ( -6.7 percent). The latter result is consistent with our simple theoretical framework, that predicts a pool of young higher-rank co-wives smaller than the pool of young unmarried men, so that some of them are not sexually active. ${ }^{48}$

Next, we investigate whether living arrangements among spouses may also play a role. ${ }^{49}$ In Table 3 , the effect of the slave trade on HIV infection is relatively similar for married women and men who cohabit (Models 2 and 4), with a 5.7 and 6.9 percent increase in the infection probability, respectively. However, for non-cohabiting married women (Model 1), the magnitude of the effect is considerably larger, implying an over 8.2 percent increase in the incidence of the disease within this group, while it is nearly nil for

\footnotetext{
${ }^{48}$ The corresponding 2SLS estimates (Table A15) show for unmarried individuals a negative effect, which is largely driven by the larger and still negative effect on unmarried men. For married individuals the magnitude of the effect is larger and, for married women, more than double if compared to OLS, while for married men it remains relatively stable, and it turns negative for unmarried women. Since in polygynous unions the average number of wives is equal to 2.35 , the relative size of the coefficients for married women vs married men (i.e., 0.007 vs 0.003 in Models 3 and 4 of Table A15) is quantitatively consistent with a multiplicative effect on women's infection rates.

${ }^{49}$ Residential patterns are measured using a dummy variable that captures the absence of co-residence, by taking value one if a partner is staying elsewhere, and zero otherwise.
} 
Table 3: HIV and the Slave Trade by Co-residence

\begin{tabular}{lcccc}
\hline & & & HIV & \\
& $(1)$ & $(2)$ & $(3)$ & $(4)$ \\
\hline Slave Trade & 0.00621 & 0.00263 & 0.00000216 & 0.00313 \\
& $(0.00338)$ & $(0.00136)$ & $(0.00581)$ & $(0.00151)$ \\
& {$[0.00373]$} & {$[0.00308]$} & {$[0.00470]$} & {$[0.00303]$} \\
& $\{0.014\}$ & $\{0.002\}$ & $\{0.999\}$ & $\{0.001\}$ \\
Controls & $\langle 0.045\rangle$ & $\langle 0.232\rangle$ & $\langle 1.000\rangle$ & $\langle 0.219\rangle$ \\
Country FE & Yes & Yes & Yes & Yes \\
\hline Adj. R-sq. & Yes & Yes & Yes & Yes \\
Observations & 0.092 & 0.097 & 0.144 & 0.103 \\
DHS Clusters & 8858 & 48510 & 3768 & 37936 \\
Ethnicities & 4125 & 6678 & 2284 & 6316 \\
Sample & 285 & 308 & 211 & 256 \\
& Married & Married & Married & Married \\
& Women & Women & Men & Men \\
& No Co-res. & Co-res. & No Co-res. & Co-res. \\
\hline
\end{tabular}

Note: OLS estimates. HIV is a dummy variable for testing positive to HIV. Slave Trade is the natural log of 0.01 plus transatlantic slave exports normalized by ethnic land area. Clustered robust standard errors at a DHS cluster level in parentheses. Clustered robust standard errors at an ethnicity level in square brackets. Randomization inference based $p$-values with individual level treatment assignment and clustering at an ethnicity level in curly brackets. Randomization inference based $p$-values with ethnicity level treatment assignment and clustering at an ethnicity level in angle brackets. The controls include: Regional GDP 2000, Population Density 2000, Population Density 1800, Rugged Terrain, Mean Elevation, Water Basins, Rainfall, Temperature, Soil PH, Soil Nutrients Availability, Growing Season, Colonial Routes, Colonial Railways, Christian Missions, Year of the Survey, Age, Sex, Marital Status, Education, Religion, Employment, Wealth, Relationship to the Head, Age of the Household Head, Sex of the Household Head, and Number of Household Members.

men in a similar position (Model 3)..$^{50}$ This suggests that non-cohabiting married women may adopt a riskier sexual behavior by cheating on their partners. If this were the case, their increased likelihood to become infected would then be likely to be transmitted to their husbands and the cohabiting other wives, pointing to female marital infidelity as a crucial transmission channel. ${ }^{51}$

\section{Channels of Transmission}

The previous section has uncovered a robust relationship between the transatlantic slave trade and the contemporaneous spread of the HIV epidemic and has also documented that the effect is stronger for non-cohabiting married women. These findings suggest

\footnotetext{
${ }^{50}$ No effect is found for unmarried individuals. We do not report these findings since for them the variation in co-residence only comes from those with a partner, who represent quite a small minority (only about 1,800$)$.

${ }^{51}$ 2SLS estimates in Table A16 show that for non-cohabiting married women the size of the coefficient - and consequently the percent increase in infection - doubles, while for non-cohabiting married men it turns negative.
} 
that the legacy of the trade may be conducive to social and sexual behaviors that favor a higher rate of transmission of HIV. In this section, we present evidence to support the conjecture that the channel of transmission may be represented by the influence exerted by the transatlantic slave trade on family structure, through the reinforcement of the diffusion of polygyny. The latter is associated with absence of co-residence and female infidelity. The resulting promiscuous sexual mores explain the diffusion of HIV infection and its gendered pattern.

We start by investigating whether risky sexual behavior, as captured by concurrent partnerships for married individuals, does represent a prominent proximate risk factor for HIV contagion, a fact that is well established in the medical literature. In Table 4, we regress the dummy for whether the respondent is positive to HIV testing on infidelity (i.e., the dummy for a positive number of extramarital partners in the last 12 months) and, to evaluate behavioral differences between men and women, once again we split the sample by gender. ${ }^{52}$ In Model 1 we find that a woman who has had extramarital affairs does show a higher probability of being infected. For unfaithful women, a one standard deviation in infidelity increases infection by as much as 19.6 percent, relative to the sample mean of the dependent variable, while in Model 2, for men, the increase reduces to 11.9 percent, pointing to gender differences in the prevalence of HIV for unfaithful individuals. ${ }^{53}$

The link between infidelity and HIV must be taken with caution, since it likely involves reverse causality. It is then natural to investigate what in turn determines the propensity to become involved in extramarital relationships. In Table 5, we turn to the slave trade as a potential fundamental determinant of infidelity. In Model 1 we start by examining the influence of the slave trade on the likelihood that partners do not live together, a habit which is particularly common in polygynous unions for co-wives of a higher rank, and whose likelihood is shown to increase by 2.1 percent with the intensity of the trade. Next, we show that the slave trade exerts a stronger influence on female, compared to male, infidelity, with a 5.2 and 1.9 increase, respectively (Models 2 and 3). Finally, in Models 4 and 5, we divide the sample according both to gender and co-residence patterns combined, to uncover an increase of HIV incidence as high as 37.4 percent for married women who do not live with their husbands (i.e., prevalently, higher-rank wives), while

\footnotetext{
${ }^{52}$ Our dummy for infidelity reflects whether an individual had any extramarital partner in the last 12 months, therefore it does not capture the number of extramarital partners. As a consequence, one may be concerned about variations in the number of extramarital partners (i.e., the intensive margin) across unfaithful individuals, depending on whether they are polygynous or monogamous. However, in the 12 months, the number of extramarital partners for unfaithful women in polygyny and monogamy is very similar (1.085 and 1.095, respectively). Therefore, the intensive margin of the phenomenon should not be a concern.

${ }^{53}$ Since in Table 4 the treatment (infidelity) varies at an individual level, we only report standard errors at the DHS cluster level, to take into account the survey design of the DHS. The same applies to Table 6 where the treatment is polygyny.
} 


\begin{tabular}{lcc}
\hline & & HIV \\
& $(1)$ & $(2)$ \\
\hline Infidelity & 0.0516 & 0.0153 \\
& $(0.00410)$ & $(0.00248)$ \\
Controls & Yes & Yes \\
Country FE & Yes & Yes \\
\hline Adj. R-sq. & 0.139 & 0.098 \\
Observations & 95145 & 82569 \\
DHS Clusters & 6743 & 6744 \\
Sample & Women & Men \\
\hline
\end{tabular}

Note: OLS estimates. HIV is a dummy variable for testing positive to HIV. Infidelity is a dummy variable for having had extramarital sexual partners. Clustered robust standard errors at a DHS cluster level in parentheses. The controls include: Regional GDP 2000, Population Density 2000, Population Density 1800, Rugged Terrain, Mean Elevation, Water Basins, Rainfall, Temperature, Soil PH, Soil Nutrients Availability, Growing Season, Colonial Routes, Colonial Railways, Christian Missions, Year of the Survey, Age, Marital Status, Education, Religion, Employment, Wealth, Relationship to the Head, Age of the Household Head, Sex of the Household Head, and Number of Household Members.

for married women in coresidence the effect is negative (i.e., a 2.7 percent decrease).

The patterns emerging so far, that point to a stronger influence of the slave trade on HIV infection for married but non-cohabiting women, are consistent with the diffusion of polygyny. In Table 6, we regress infidelity on polygyny and again we uncover a positive correlation for women (for a one standard deviation in polygyny, female infidelity increases by 33.3 percent, relative to the sample mean), but not for men (for whom the corresponding increase is less than 1 percent). The table also shows that polygyny exerts a significant and positive effect on absence of co-residence (11.5 percent) and HIV infection (4.2 percent).

Overall, the suggestive evidence emerging from Tables 5 and 6 supports the hypothesis that the diffusion of polygyny determines a social environment in which co-wives often do not live with their husbands and may be involved in promiscuous behavior leading to infection. This is likely to be particularly common for second and third co-wives (and those of higher order). In fact, among the co-wives who report their rank - only 17,472 - almost 23 percent of the second co-wives and 21 percent of the third co-wives do not reside with the husband, compared to 19 percent of the first co-wives. ${ }^{54}$ At the same time, the rate of extramarital affairs increases from 2 percent for first co-wives to 4.1 and 3.4 percent, respectively, for second and third ones. This additional information confirms that separate living arrangements, as well as marital infidelity, are particularly

\footnotetext{
${ }^{54} \mathrm{~A}$ co-wife rank reflects the rank of the respondent among the partner's wives, by chronological order of the respective marriages. Since the sample of rank-reporting co-wives is so small, we do not report the full set of summary statistics.
} 
Table 5: Infidelity, No Co-residence, and the Slave Trade

\begin{tabular}{lccccc}
\hline & No Co-residence & \multicolumn{3}{c}{ Infidelity } \\
& $(1)$ & $(2)$ & $(3)$ & $(4)$ & $(5)$ \\
\hline Slave Trade & 0.00218 & 0.00383 & 0.00233 & 0.00841 & -0.00182 \\
& $(0.00112)$ & $(0.00144)$ & $(0.00196)$ & $(0.00356)$ & $(0.000718)$ \\
& {$[0.00159]$} & {$[0.00159]$} & {$[(0.00265]$} & {$[(0.00560]$} & {$[0.00107]$} \\
& $\{0.000\}$ & $\{0.000\}$ & $\{0.004\}$ & $\{0.000\}$ & $\{0.000\}$ \\
Controls & $\langle 0.259\rangle$ & $\langle 0.071\rangle$ & $\langle 0.467\rangle$ & $\langle 0.071\rangle$ & $\langle 0.032\rangle$ \\
Country FE & Yes & Yes & Yes & Yes & Yes \\
\hline Adj. R-sq. & Yes & Yes & Yes & Yes & Yes \\
Observations & 0.404 & 0.257 & 0.239 & 0.093 & 0.036 \\
DHS Clusters & 103145 & 95165 & 82602 & 8822 & 48270 \\
Ethnicities & 6750 & 6743 & 6744 & 4113 & 6677 \\
Sample & 308 & 308 & 308 & 285 & 308 \\
& Full & Women & Men & Married & Married \\
& & & & Women & Women \\
& & & & No Co-res. & Co-res. \\
\hline
\end{tabular}

Note: OLS estimates. No Co-residence is a dummy variable for a partner staying elsewhere. Infidelity is a dummy variable for having had extramarital sexual partners. Slave Trade is the natural log of 0.01 plus transatlantic slave exports normalized by ethnic land area. Clustered robust standard errors at a DHS cluster level in parentheses. Clustered robust standard errors at an ethnicity level in square brackets. Randomization inference based $p$-values with individual level treatment assignment and clustering at an ethnicity level in curly brackets. Randomization inference based $p$-values with ethnicity level treatment assignment and clustering at an ethnicity level in angle brackets. The controls include: Regional GDP 2000, Population Density 2000, Population Density 1800, Rugged Terrain, Mean Elevation, Water Basins, Rainfall, Temperature, Soil PH, Soil Nutrients Availability, Growing Season, Colonial Routes, Colonial Railways, Christian Missions, Year of the Survey, Age, Sex, Marital Status, Education, Religion, Employment, Wealth, Relationship to the Head, Age of the Household Head, Sex of the Household Head, and Number of Household Members. Sex is dropped from Models 1, 2, 4 and 5. Marital Status is dropped from Models 4 and 5.

common for co-wives of higher rank. This behavior can be attributed to the fact that they are neglected and dissatisfied within a polygynous union (Poku, 2005; Ogundipe-Leslie, 1994).

Lastly, in Table 7, we examine whether the intensity of transatlantic trade exposure still predicts contemporaneous polygyny. ${ }^{55}$ In Model 1 we present a simple correlation showing a sizeable increase in polygyny by 17 percent as the slave trade increase by a one standard deviation but, after adding the usual controls and country fixed effects, the impact turns nil (Model 2) and even negative (-4.7, in Model 3) ${ }^{56}$ However, when we distinguish among age groups, we uncover heterogeneities across cohorts, with the likelihood of polygyny increasing more intensively with the trade as age increases. ${ }^{57}$ Overall,

\footnotetext{
${ }^{55}$ As in Dalton and Leung (2014), regressions are run over the married women sample.

${ }^{56}$ Across slightly different specifications/samples, with controls and country fixed effects, the effect is insignificant in Dalton and Leung (2014) and Teso (2019), and negative in the working paper version of Fenske (2015), pointing to a non-robust influence of the average effect of the slave trade.

${ }^{57}$ We replace the age of the respondent with dummies for respondents aged 15-19, 20-29, 30-44, and 45-59, with the 15-19 as the omitted group.
} 
Table 6: Infidelity, No Co-residence, HIV, and Polygyny

\begin{tabular}{lcccc}
\hline & $(1)$ & $(2)$ & $(3)$ & $(4)$ \\
& Infidelity & Infidelity & No Co-residence & HIV \\
\hline Polygyny & 0.0117 & 0.00406 & 0.0413 & 0.00879 \\
& $(0.00273)$ & $(0.00683)$ & $(0.00376)$ & $(0.00271)$ \\
Controls & Yes & Yes & Yes & Yes \\
Country FE & Yes & Yes & Yes & Yes \\
\hline Adj. R-sq. & 0.106 & 0.154 & 0.410 & 0.099 \\
Observations & 55952 & 45241 & 99375 & 100345 \\
DHS Clusters & 6340 & 6682 & 6735 & 6734 \\
Sample & Women & Men & Full & Full \\
\hline
\end{tabular}

Note: OLS estimates. Infidelity is a dummy variable for having had extramarital sexual partners. No Co-residence is a dummy variable for a partner staying elsewhere. HIV is a dummy variable for testing positive to HIV. Polygyny is a dummy variable for belonging to a polygynous household. Slave Trade is the natural log of 0.01 plus transatlantic slave exports normalized by ethnic land area. Clustered robust standard errors at a DHS cluster level in parentheses. The controls include: Regional GDP 2000, Population Density 2000, Population Density 1800, Rugged Terrain, Mean Elevation, Water Basins, Rainfall, Temperature, Soil PH, Soil Nutrients Availability, Growing Season, Colonial Routes, Colonial Railways, Christian Missions, Year of the Survey, Age, Sex, Marital Status, Education, Religion, Employment, Wealth, Relationship to the Head, Age of the Household Head, Sex of the Household Head, and Number of Household Members. Sex is dropped from Models 1 and 2 .

without country fixed effects (Model 4), the slave trade provokes a 4.4 percent increase in polygyny, through its positive influence for the two oldest cohorts (i.e., for women 30 or older). With country fixed effects (Model 5), the overall effect becomes negative albeit small ( -0.3 percent), even though it remains positive for the oldest (age 45 and above) cohort. These findings can be explained by several factors. First of all, they may reflect an actual decline in the prevalence of polygyny for the younger generations, as a result of social change. ${ }^{58}$ Nevertheless, due to cultural persistence, absence of coresidence among spouses and female infidelity may continue after a decline of polygyny, with a lasting influence on infection. The observed patterns may also capture the fact that the legal practice of polygyny has been challenged in several African countries, with many countries introducing bans and even punishments which may have induced underreporting. ${ }^{59}$ Underreporting can also occur unintentionally, since women may actually not know whether their husbands haves other wives, especially in the case of higher-rank, younger co-wives who do not live with them. At the same time, women may be aware of other co-wives but still fail to report them, especially in more progressive areas where being in a polygynous union may carry a social stigma.

\footnotetext{
${ }^{58} \mathrm{~A}$ decline of polygyny has also been documented by Fenske (2015) and Rijpma and Carmichael (2016).

${ }^{59}$ Since the legal status of polygyny is established at the country level, it is captured by country fixed effects. However, our results are confirmed for (unreported) separate regressions on the sub-sample of countries were polygyny is legal (or accepted under customary law) and the sub-sample where it is illegal.
} 
Table 7: Polygyny and the Slave Trade

\begin{tabular}{|c|c|c|c|c|c|}
\hline & $(1)$ & $(2)$ & $\begin{array}{c}\text { Polygyny } \\
(3)\end{array}$ & $(4)$ & $(5)$ \\
\hline \multirow[t]{5}{*}{ Slave Trade } & 0.0174 & 0.0000201 & -0.00514 & -0.0115 & -0.0174 \\
\hline & $(0.00227)$ & $(0.00203)$ & $(0.00234)$ & $(0.00446)$ & $(0.00463)$ \\
\hline & {$[0.0108]$} & {$[0.00549]$} & {$[0.00399]$} & {$[0.00611]$} & {$[0.00686]$} \\
\hline & $\{0.000\}$ & $\{0.987\}$ & $\{0.000\}$ & $\{0.000\}$ & $\{0.000\}$ \\
\hline & $\langle 0.077\rangle$ & $\langle 0.996\rangle$ & $\langle 0.135\rangle$ & $\langle 0.011\rangle$ & $\langle 0.000\rangle$ \\
\hline \multirow[t]{5}{*}{ Slave Trade*Age 20-30 } & & & & 0.00806 & 0.00838 \\
\hline & & & & $(0.00449)$ & $(0.00446)$ \\
\hline & & & & {$[0.00635]$} & {$[0.00644]$} \\
\hline & & & & $\{0.000\}$ & $\{0.074\}$ \\
\hline & & & & $\langle 0.000\rangle$ & $\langle 0.040\rangle$ \\
\hline \multirow[t]{5}{*}{ Slave Trade*Age $30-44$} & & & & 0.0149 & 0.0158 \\
\hline & & & & $(0.00476)$ & $(0.00470)$ \\
\hline & & & & {$[0.00846]$} & {$[0.00872]$} \\
\hline & & & & $\{0.000\}$ & $\{0.000\}$ \\
\hline & & & & $\langle 0.000\rangle$ & $\langle 0.000\rangle$ \\
\hline \multirow[t]{5}{*}{ Slave Trade*Age 45 and Over } & & & & 0.0232 & 0.0250 \\
\hline & & & & $(0.00643)$ & $(0.00636)$ \\
\hline & & & & {$[0.0104]$} & {$[0.0105]$} \\
\hline & & & & $\{0.000\}$ & $\{0.000\}$ \\
\hline & & & & $\langle 0.000\rangle$ & $\langle 0.000\rangle$ \\
\hline Controls & No & Yes & Yes & Yes & Yes \\
\hline Country FE & No & No & Yes & No & Yes \\
\hline Adj. R-sq. & 0.005 & 0.187 & 0.201 & 0.187 & 0.201 \\
\hline Observations & 55809 & 54777 & 54777 & 54777 & 54777 \\
\hline DHS Clusters & 6343 & 6337 & 6337 & 6337 & 6337 \\
\hline Ethnicities & 305 & 305 & 305 & 305 & 305 \\
\hline \multirow[t]{2}{*}{ Sample } & Married & Married & Married & Married & Married \\
\hline & Women & Women & Women & Women & Women \\
\hline
\end{tabular}

Note: OLS estimates. Polygyny is a dummy variable for belonging to a polygynous household. Slave Trade is the natural $\log$ of 0.01 plus transatlantic slave exports normalized by ethnic land area. Clustered robust standard errors at a DHS cluster level in parentheses. Clustered robust standard errors at an ethnicity level in square brackets. Randomization inference based $p$-values with individual level treatment assignment and clustering at an ethnicity level in curly brackets. Randomization inference based $p$-values with ethnicity level treatment assignment and clustering at an ethnicity level in angle brackets. The controls include: Regional GDP 2000, Population Density 2000, Population Density 1800, Rugged Terrain, Mean Elevation, Water Basins, Rainfall, Temperature, Soil PH, Soil Nutrients Availability, Growing Season, Colonial Routes, Colonial Railways, Christian Missions, Year of the Survey, Age, Education, Religion, Employment, Wealth, Relationship to the Head, Age of the Household Head, Sex of the Household Head, and Number of Household Members. 
To investigate the issue of underreporting in further detail, we code a dummy variable for men that report more than one wife when a wife does not report any co-wife, or does not respond to the question asking the number of co-wives. ${ }^{60}$ We interpret this variable as a proxy for underreporting a woman's own status as a co-wife. The sample includes almost 1,100 women who report inconsistencies with their husband in answering to the question about the number of wives/co-wives. In Model 2 of Table A9, we regress the proxy for underreporting polygyny on distance from the coast. The hypothesis is that, in coastal areas, individuals tend to be more progressive and therefore more reluctant to admit to be part of a polygynous relationship. We interpret the negative size of the coefficient as evidence that indeed the practice of keeping co-wives who do not know and/or do not admit to be part of a polygynous union is more diffused in the less conservative areas closer to the coast, which are also the more intensively affected by the slave trade. ${ }^{61}$ This implies that the results from regressing polygyny on the slave trade are likely to be severely downward biased, especially for higher-rank, younger co-wives. ${ }^{62}$

Taken together, the evidence we collect points to a crucial role for polygyny and marital dissatisfaction, especially for younger co-wives, in the link between the transatlantic slave trade and the contemporaneous disease environment. Since an unfaithful, infected co-wife can transmit the virus to the other co-wives through the husband, a multiplicative effect among women is triggered by contagion across all co-wives, independent on whether they have cheated or not.

\section{The Slave Trade and Female Sexuality}

Our investigation has so far focused on whether the transatlantic slave trade represents a long-term determinant of HIV infection and its gendered pattern. The evidence we presented is consistent with our hypothesis that, by reinforcing the institution of polygyny, the transatlantic trade has influenced the evolution of behavioral norms. As a result, in areas more exposed to the trade, married women are more promiscuous and more vulnerable to the disease. However, alternative explanations can also be envisioned. The transatlantic trade may have exerted an influence on contemporaneous social and sexual mores not only - indirectly - through polygyny, but also through a direct effect on norms

\footnotetext{
${ }^{60}$ This is done by generating a variable that records the maximal number of wives reported by the husband, and then coding a new variable which is taking value one if the husband reports a number of wives larger than one and the wives report zero co-wives or do not respond.

${ }^{61} \mathrm{~A}$ one standard deviation increase in distance from the cost implies a 16.1 percent decrease in underreporting.

${ }^{62} \mathrm{Absence}$ of co-residence is most frequent among youngest (15-19) married women, and underreporting co-wives is highest among women who do not co-reside.
} 
about family formation, marital infidelity, and extramarital sexual behavior. Such norms are indeed the object of a large historical and anthropological literature.

A related discussion on the supposedly higher propensity to promiscuity in Africa, if compared to other continents, arose in connection with the explosion of the HIV epidemic. Anthropologists (e.g., Goody, 1976) and demographers (e.g., Caldwell, Caldwell, and Quiggin, 1989) have argued that Africa was historically associated with higher levels of extramarital activity and more permissive female sexuality, if compared to Eurasia. This has been attributed to its relatively poor soils, that prevented the development of the means of protection and transmission of wealth prevailing in Eurasia, such as women's virginity and chastity and the provision of dowries. By contrast, under the local system of subsistence farming, in Africa wealth depended mainly on acquiring wives - often in exchange of a bride price - and children. ${ }^{63}$ This resulted in an emphasis on fostering female fertility, rather than chastity. The view according to which Africa historically displayed more permissive sexual mores, particularly for females, is challenged, among others, by Ahlberg (1994). It is also at least partially contradicted by Bosman, a merchant in the service of the Dutch West India Company who, in his 1704 diaries, provides an accurate and authoritative description of the Guinean Slave Coast (Bosman, 1907). In particular, he narrates that, even in areas with widespread polygyny, adultery was viewed as a crime, third in gravity after murder and theft. However, to the best of our knowledge, within the above mentioned literature no connection between sexuality and the slave trade was ever proposed. ${ }^{64}$ In fact, Ahlberg (1994) conjectures that, since the slave trade involved taking individuals away from their communities, its impact was not as overwhelming as that of direct colonial rule and the associated process of christianization, that affected the same communities in a subsequent stage.

Despite the absence of even anecdotal evidence on hypothetical direct links between the slave trade and sexuality in Africa, we turn to the potentially relevant data in Murdock (1967), which are available at the ethnicity level. In particular, we look at two variables, respectively capturing Norms of Premarital Sexual Behavior for Girls and Mode of Marriage. We view this further exploration as merely suggestive, since the small sample size prevents us from pinning down the precise mechanisms being involved.

Norms of Premarital Sexual Behavior for Girls categorizes the standards of sex behavior prevailing for unmarried females, according to their degree of relative permissiveness, into the following six groups: premarital sex allowed and not sanctioned unless pregnancy results (Allowed); premarital sex precluded by a very early age of marriage for females, at

\footnotetext{
${ }^{63}$ See also the discussion and the references in Sub-section 2.1.

${ }^{64}$ For the sake of comparison, the literature on the effects of American slavery on the "black family" and sexual behavior in the US is instead vast.
} 
Table 8: Norms of Premarital Sexual Behavior for Girls and the Slave Trade

\begin{tabular}{lcccccc}
\hline & $(1)$ & $(2)$ & $(3)$ & $(4)$ & $(5)$ & $(6)$ \\
& Allowed & Early Marriage & Free & Virginity & Weakly Censored & Prohibited \\
\hline Slave Trade & 0.00900 & -0.00387 & -0.00448 & -0.00503 & 0.00703 & -0.00265 \\
& $(0.00731)$ & $(0.0151)$ & $(0.0357)$ & $(0.0188)$ & $(0.0203)$ & $(0.0106)$ \\
& $\{0.591\}$ & $\{0.859\}$ & $\{0.899\}$ & $\{0.853\}$ & $\{0.752\}$ & $\{0.882\}$ \\
Controls & No & No & No & No & No & No \\
Country FE & Yes & Yes & Yes & Yes & Yes & Yes \\
\hline Adj. R-sq. & 0.014 & 0.082 & 0.117 & 0.306 & -0.098 & -0.137 \\
Observations & 83 & 83 & 83 & 83 & 83 & 83 \\
\hline
\end{tabular}

Note: OLS estimates. Slave Trade is the natural log of 0.01 plus transatlantic slave exports normalized by ethnic land area. Robust standard errors in parentheses. Randomization inference based $p$-values with individual level treatment assignment at an ethnicity level in curly brackets.

or before puberty (Early Marriage); premarital sex freely permitted (Free); insistence on virginity (Virginity); premarital sex prohibited but weakly sanctioned and not infrequent (Weakly Censored); and premarital sex relations prohibited, strongly sanctioned, and rare (Prohibited). For Africa, only 83 observations are available, out of the 343 ethnic groups in our sample. In Table 8, we regress the corresponding dummy variables on the transatlantic slave trade. ${ }^{65}$ In terms of percentage points, the effects we detect in association with a one standard deviation increase in the slave trade are modest, with a maximal one in Model 1 at 1.8. Moreover, the high $p$-values obtained from randomization inference suggest that the sharp null is (almost) never rejected. Therefore, we can conclude that there is no compelling evidence supporting the presence of a direct influence of the trade on these domains.

Since a link has been suggested between female sexuality and the prevailing mode of obtaining a wife, we also consider the variable Mode of Marriage, that corresponds to the following categorization: No Consideration; transfer of property to the bride's family (Bride Price); transfer of services, e.g. labor, to the bride's family (Bride Service); transfer from the bride's family (Dowry); transfer of a sister or other female relative of the groom in exchange for the bride (Female Exchange); and small or symbolic transfer (Token Bride Price). Based on this categorization, again we generate a set of appropriately defined dummy variables. For Africa we collect 208 observations out of 343 ethnic groups. In Table 9, we regress the dummy variables on the transatlantic trade and we obtain no conclusive evidence. ${ }^{66}$ Thus, the additional exploration reported in this section reassures

\footnotetext{
${ }^{65}$ Since in the ethnicity data by Murdock (1967) there is no variation within each ethnic group, in Tables 8 and 9 , for the computation of the standard errors we apply the robust option (in parentheses). We also report randomization inference based $p$-values with individual level treatment assignment at an ethnicity level (in curly brackets). To account for spatial correlation across ethnicities, in the corresponding Tables A17 and A18 we compute Conley (1999) spatial HAC standard errors for a window of $200 \mathrm{~km}$.

${ }^{66}$ Dowry is not reported since the variable does not vary within country.
} 
Table 9: Mode of Marriage and the Slave Trade

\begin{tabular}{lccccc}
\hline & $(1)$ & $(2)$ & $(3)$ & $(4)$ & $(5)$ \\
& No Consideration & Bride Price & Bride Service & Female Exchange & $\begin{array}{c}\text { Token Bride } \\
\text { Slave Trade }\end{array}$ \\
& 0.000912 & -0.0117 & 0.0171 & -0.00927 & 0.00302 \\
& $(0.00187)$ & $(0.0146)$ & $(0.0119)$ & $(0.00579)$ & $(0.00956)$ \\
& $\{0.896\}$ & $\{0.427\}$ & $\{0.111\}$ & $\{0.123\}$ & $\{0.764\}$ \\
\hline Controls & No & No & No & No & No \\
Country FE & Yes & Yes & Yes & Yes & Yes \\
\hline Adj. R-sq. & 0.027 & 0.124 & 0.148 & -0.047 & 0.006 \\
Observations & 208 & 208 & 208 & 208 & 208 \\
\hline
\end{tabular}

Note: OLS estimates. Slave Trade is the natural log of 0.01 plus transatlantic slave exports normalized by ethnic land area. Robust standard errors in parentheses. Randomization inference based $p$-values with individual level treatment assignment at an ethnicity level in curly brackets.

us about the fact that the impact of the slave trade on HIV infection is likely to be primarily transmitted through the channels we identified in Sections 5 and 6.

\section{Conclusion}

The paper has shown how the transatlantic slave trade is persistently affecting the contemporaneous disease environment in sub-Saharan Africa, with higher rates of HIV infection, particularly for women, in areas that were more intensively affected by the trade. We also offer evidence on the channels driving these outcomes, that point to family structure and social and sexual behavior. In areas that were more exposed to the trade, we observe a lower likelihood of co-residence for married individuals and a higher likelihood of female infidelity. We interpret these findings as the consequence of unsatisfying marital relationships for higher-rank co-wives within polygynous households. Their promiscuous sexual behavior increases their exposure to the risk of infection, with a multiplier effect, through the husbands, spreading the disease to other co-wives.

Policy reports by international organizations (UNAIDS, 2016b) stress the disproportionate impact of HIV on women, especially in sub-Saharan Africa, and search for tools for playing an active role in the struggle against AIDS. Harmful gender norms, inequalities between the sexes, and women's rights violations are among the reasons why women and girls are more vulnerable to the virus. Women's empowerment, starting from access to comprehensive sexuality education and knowledge, has been indicated as a crucial intermediate goal. Since sexual habits involving multiple partners are a central driver of the spread of the epidemic, it is crucial to understand their determinants, including the social determinants of extramarital concurrent partnerships. Public opinion as well as policymakers are well aware of the potential link between the latter and the practice of 
polygyny. A recent marriage bill legalizing polygamy in Kenya has ignited controversies, as HIV activists claim it may increase the spread of the disease (Maroncha, 2014). Polygyny is commonly accepted in Kenya according to customary law, but it was previously outlawed. The unsatisfying nature of polygynous marriages, leading to female infidelity, and the multiplying effect of the presence of co-wives sharing the same husband, have been explicitly recognized as drivers of HIV spread within the debate that followed the enactment of the bill. To document and quantify the strength of the links between HIV prevalence, on the one hand, and sexual behavior and social and family structure, on the other, and to point to the demographic disruption brought about by the transatlantic slave trade as a fundamental risk factor, is the main contribution of this paper to the policy debate.

\section{REFERENCES}

Acemoglu, D., Johnson, S. and Robinson, J.A., 2002. Reversal of Fortune: Geography and Institutions in the Making of the Modern World Income Distribution. Quarterly Journal of Economics 117, 1231-1294.

Ahlberg, B.M., 1994. Is There a Distinct African Sexuality? A Critical Response to Caldwell. Africa: Journal of the International African Institute 64, 220-242.

Alesina, A. and Giuliano, P., 2015. Culture and Institutions. Journal of Economic Literature 53, 898-944.

Altonji, J.G., Elder, T.E. and Taber, C.R., 2005. Selection on Observed and Unobserved Variables: Assessing the Effectiveness of Catholic Schools. Journal of Political Economy 113, 151-184.

Anderson, S., 2018. Legal Origins and Female HIV. American Economic Review 108, 1407-1439.

Ashby, B. and Gupta S., 2013. Sexually Transmitted Infections in Polygamous Mating Systems. Philosophical Transactions of the Royal Society B: Biological Sciences 368, 20120048.

Ashraf, N., Bandiera, O. and Jack, K., 2014. No Margin, No Mission? A Field Experiment on Incentives for Public Service Delivery. Journal of Public Economics 120, $1-17$.

Auvert, B., Taljaard, D., Lagarde, E., Sobngwi-Tembekou, J., Sitta, R. and Puren, A., 2005. Randomized, Controlled Intervention Trial of Male Circumcision for Reduction of HIV Infection Risk: The ANRS 1265 Trial. PLoS Med 2, 1112-1122.

Barrios, T., Diamond, R., Imbens, G.W. and Kolesar, M., 2012. Clustering, Spatial Correlations, and Randomization Inference. Journal of the American Statistical Association 107, 578-591. 
Becker, G.S., 1974. A Theory of Marriage: Part ii. Journal of Political Economy 82, S11-S26, Part II.

Becker, G.S., 1973. A Theory of Marriage: Part i. Journal of Political Economy 81, 813-846.

Bisin, A. and Verdier, T., 2001. The Economics of Cultural Transmission and the Dynamics of Preferences. Journal of Economic Theory 97, 298-319.

Boserup, E., 1970. Women's Role in Economic Development. George Allen and Unwin, London.

Bosman, W., 1907. A New and Accurate Description of the Coast of Guinea, Divided into the Gold, the Slave, and the Ivory Coasts. Elder, Dempster \& Co., Liverpool.

Brasio, A., 1958. Monumenta Missionaria Africana. Coligida e Anotada pelo Padre Antonio Brasio. Agência Geral do Ultramar, Lisbon.

Burke, M., Gong, E. and Jones, K., 2015. Income Shocks and HIV in Africa. Economic Journal 125, 1157-1189.

Cagé, J. and Rueda, V., 2017. Sex and the Mission: The Conflicting Effects of Early Christian Investments on the HIV Epidemic in Sub-Saharan Africa. CEPR Discussion Paper No. 12192.

Caldwell, J.C., Caldwell, P. and Quiggin, P., 1989. The Social Context of AIDS in Sub-Saharan Africa. Population and Development Review 15, 185-234.

Caldwell, J.C., Orubuloye, I.O. and Caldwell, P., 1991. The Destabilization of the Traditional Yoruba Sexual System. Population and Development Review 17, 229-262.

Caraël, M., 1995. Sexual Behaviour. In John Cleland, J.G. and Ferry, B. (eds.), Sexual Behaviour and AIDS in the Developing World. Francis and Taylor, Oxon, 75-123.

Ciment, J., 2007. Atlas of African-American History, Revised Edition. Facts On File, New York.

Conley, T.G., 1999. GMM Estimation with Cross Sectional Dependence. Journal of Econometrics 92, 1-45.

Dalton, J.T. and Leung, T.C., 2014. Why Is Polygyny More Prevalent in Western Africa? An African Slave Trade Perspective. Economic Development and Cultural Change 62, 599-632.

Delavande, A. and Kohler, H.-P., 2016. HIV/AIDS-related Expectations and Risky Sexual Behavior in Malawi. Review of Economic Studies 83, 118-164.

de Walque, D., 2007. How Does the Impact of an HIV/AIDS Information Campaign Vary with Educational Attainment? Evidence from Rural Uganda. Journal of Development Economics 84, 686-714.

Duflo, E., Dupas, P. and Kremer, M., 2015. Education, HIV, and Early Fertility: Experimental Evidence from Kenya. American Economic Review 105, 2757-2797. 
Dupas, P., 2011. Do Teenagers Respond to HIV Risk Information? Evidence from a Field Experiment in Kenya. American Economic Journal: Applied Economics 3, 1-34.

Eaton, J.W., Takavarasha, F.R., Schumacher, C.M., Mugurungi, O., Garnett, G.P., Nyamukapa, C. and Gregson, S., 2014. Trends in Concurrency, Polygyny, and Multiple Sex Partnerships during a Decade of Declining HIV Prevalence in Eastern Zimbabwe. Journal of Infectious Diseases 210, Suppl. 2, S562-S568.

Edlund, L. and $\mathrm{Ku}, \mathrm{H} ., 2011$. The African Slave Trade and the Curious Case of General Polygyny. MPRA Paper No. 52735.

Eltis, D., 2008. The U.S. Transatlantic Slave Trade, 1644-1867: An Assessment. Civil War History 54, 347-378.

Epstein, H. and Morris, M., 2011. Concurrent Partnerships and HIV: An Inconvenient Truth. Journal of the International AIDS Society 14, 13.

Epstein, H. and Stanton, D., 2010. Is Polygamy Really Benign? AIDS 24, 1791-1792. Eyawo, O., de Walque, D., Ford, N., Gakii, G., Lester, R.T. and Mills, E.J., 2010. HIV Status in Discordant Couples in Sub-Saharan Africa: A Systematic Review and Meta-analysis. Lancet Infectious Diseases 10, 770-777.

Fage, J.D., 1980. Slaves and Society in Western Africa, c. 1445 - c. 1700. Journal of African History 21, 289-310.

Fenske, J., 2015. African Polygamy: Past and Present. Journal of Development Economics 117, 58-73.

Fisher, R.A, 1935. The Design of Experiments. Oliver \& Boyd, Edinburgh.

Francis, A.M., 2008. The Economics of Sexuality: The Effect of HIV/AIDS on Homosexual Behavior in the United States. Journal of Health Economics 27, 675-689.

Galor, O. and Ashraf, Q., 2013. The Out of Africa Hypothesis, Human Genetic Diversity and Comparative Development. American Economic Review 103, 1-46.

Ghosh, T., Powell, R.L., Elvidge, C.D., Baugh, K.E., Sutton, P.C. and Anderson, S., 2010. Shedding Light on the Global Distribution of Economic Activity. Open Geography Journal 3, 147-160.

Giavazzi, F., Petkov, I. and Schiantarelli, F., 2014. Culture: Persistence and Evolution. NBER Working Paper No. 20174.

Goody, J., 1976. Production and Reproduction: A Comparative Study of the Domestic Domain. Cambridge University Press, Cambridge.

Gould, E.D., Moav, O. and Simhon, A., 2008. The Mystery of Monogamy. American Economic Review 98, 333-357.

Gray, R.H., Kigozi, G., Servadda, D., Makumbi, F., Watya, S., Nalugoda, F. and Kiwanuka, N., 2007. Male Circumcision for HIV Prevention in Men in Rakai, Uganda: A Randomized Trial. Lancet 369, 657-666. 
Greenwood, J., Kircher, P., Santos, C. and Tertilt, M., 2013. An Equilibrium Model of the African HIV/AIDS Epidemic. NBER Working Paper No. 18953.

Hall, R.E. and Jones, C.I., 1999. Why Do Some Countries Produce So Much More Output per Worker than Others? Quarterly Journal of Economics 114, 83-116.

Halperin, D.T. and Epstein, H., 2004. Concurrent Sexual Partnerships Help to Explain Africa's High HIV Prevalence: Implications for Prevention. Lancet 364, 4-6.

Hoffman, M. and Tadelis, S., 2018. People Management Skills, Employee Attrition, and Manager Rewards: An Empirical Analysis. NBER Working Paper No. 24360.

ICF International, 2012. Survey Organization Manual for Demographic and Health Surveys. MEASURE DHS. ICF International, Calverton.

Jacoby, H.G., 1995. The Economics of Polygyny in Sub-Saharan Africa: Female Productivity and the Demand for Wives in Côte d'Ivoire. Journal of Political Economy 103, 938-971.

Jankowiak, W., Sudakov, M. and Wilreker, B.C., 2005. Co-wife Conflict and Cooperation. Ethnology 44, 81-98.

Kwena, Z., Mwanzo, I., Shisanya, C., Camlin, C., Turan, J., Achiro, L. and Bukusi, E., 2014. Predictors of Extra-Marital Partnerships among Women Married to Fishermen along Lake Victoria in Kisumu County, Kenya. PLoS ONE 9, e95298.

Labat, J.-B., 1728. Nouvelle Relation de l'Afrique Occidentale. Guillaume Cavelier, Paris.

Lagerlof, N.-P., 2010. Pacifying Monogamy. Journal of Economic Growth 15, 235-262.

Lamie, K., 2007. The Impact of the Atlantic Slave Trade on West Africa: Polygyny and Female Reproductive Success. Nebraska Anthropologist 22, 16-32.

Lee, G.R. and Whitbeck, L.B., 1990. Economic Systems and Rates of Polygyny. Journal of Comparative Family Studies 21, 13-24.

Lowes, S. and Montero, E., 2018. The Legacy of Colonial Medical Campaigns in Central Africa. CEPR Discussion Paper No. 12772.

Luke, N. and Kurtz, K.M., 2002. Cross-Generational and Transactional Sexual Relations in Sub-Saharan Africa: Prevalence of Behavior and Implications for Negotiating Safer Sexual Practices. ICRW/PSI Report.

Magruder, J., 2011. Marital Shopping and Epidemic AIDS. Demography 48, 14011428.

Mah, T.L. and Halperin, D.T., 2010. Concurrent Sexual Partnerships and the HIV Epidemics in Africa: Evidence to Move Forward. AIDS and Behaviour 14, 11-16.

Mann, J. and Tarantola, D., 1998. Responding to HIV/AIDS: A Historical Perspective. Health and Human Rights 2, 5-8.

Manning, P., 1981. The Enslavement of Africans: A Demographic Model. Canadian 
Journal of African Studies 15, 499-526.

Mantovanelli, F.G., 2014. Christian Missions, HIV, and Sexual Behaviors in SubSaharan Africa. Mimeo, Boston College.

Maroncha, L., 2014. Polygamy in Kenya: A Legal Way to Spread HIV? Key Correspondents: Reporting for Action on HIV, May 1.

Mbirimtengerenji, N.D., 2007. Is HIV/AIDS Epidemic Outcome of Poverty in SubSaharan Africa? Croatian Medical Journal 48, 605-661.

Mishra, V., Vaessen, M., Ties Boerma, J.T., Arnold, F., Way, A., Barrere, B., Cross, A., Hong, R. and Sangha, J., 2006. HIV Testing in National Population-based Surveys: Experience from the Demographic and Health Surveys. Bulletin of the World Health Organization 84, 537-545.

Murdock, G.P., 1967. Ethnographic Atlas. University of Pittsburgh Press, Pittsburgh. Murdock, G.P., 1959. Africa: Its Peoples and Their Culture History. McGraw-Hill, New York.

Neelakantan, U. and Tertilt, M., 2008. A Note on Marriage Market Clearing. Economics Letters 101, 103-105.

Nunn, N., 2012. Culture and the Historical Process. Economic History of Developing Regions 27, 108-126.

Nunn, N., 2010. Religious Conversion in Colonial Africa. American Economic Review $100,147-152$.

Nunn, N., 2008. The Long-Term Effects of Africa's Slave Trades. Quarterly Journal of Economics 123, 139-176.

Nunn, N. and Wantchekon, L., 2011. The Slave Trade and the Origins of Mistrust in Africa. American Economic Review 101, 3221-3252.

Ogundipe-Leslie, M., 1994. Re-creating Ourselves: African Women \& Critical Transformations. African World Press, Trenton.

Oster, E., 2017. Unobservable Selection and Coefficient Stability: Theory and Validation. Journal of Business Economics and Statistics, forthcoming.

Oster, E., 2005. Sexually Transmitted Infections, Sexual Behavior, and the HIV/AIDS Epidemic. Quarterly Journal of Economics 120, 467-515.

Poku, N.K., 2005. Aids in Africa: How the Poor Are Dying. Polity Press, Cambridge.

Reniers, G. and Watkins, S., 2010. Polygyny and the Spread of HIV in Sub-Saharan Africa: A Case of Benign Concurrency. AIDS 24, 299-307.

Rijpma, A. and Carmichael, S.G., 2016. Testing Todd and Matching Murdock: Global Data on Historical Family Characteristics. Economic History of Developing Regions 31, $10-46$.

Satyanath, S., Voigtlander, N. and Voth, H.-J., 2017. Bowling for Fascism: Social 
Capital and the Rise of the Nazi Party. Journal of Political Economy 125, 478-526.

Shelton, J.D., 2009. Why Multiple Sexual Partners? Lancet 374, 367-369.

Shelton, J.D., 2007. Ten Myths and One Truth about Generalised HIV Epidemics. Lancet 370, 1809-1811.

Strassmann, B., 2000. Polygyny, Family Structure, and Child Mortality: A Prospective Study among the Dogon of Mali. In Cronk, L., Chagnon, N. and Irons, W. (eds.), Adaptation and Human Behavior. Aldine de Gruyer, New York, 49-67.

Tertilt, M., 2005. Polygyny, Fertility, and Savings. Journal of Political Economy 113, 1341-1371.

Teso, E., 2019. The Long-Term Effect of Demographic Shocks on the Evolution of Gender Roles: Evidence from the Trans-Atlantic Slave Trade. Journal of the European Economic Association 17, 497-534.

Texeira de Mota, A., 1974. As Viagens do Bispo D. Frei Vitorino Portuense à Guiné e a Cristianização dos Reis de Bissau. Junta de Investigações Científicas do Ultramar, Lisbon.

Thornton, J., 1983. Sexual Demography: The Impact of the Slave Trade on Family Structure. in Robinson, C. and Klein, M. (eds.), Women and Slavery in Africa. University of Wisconsin Press, Madison, 39-48.

Thornton, J., 1980. The Slave Trade in Eighteenth Century Angola: Effects on Demographic Structures. Canadian Journal of African Studies 14, 417-428.

Todd, E., 1984. L'Enfance du Monde, Structures Familiales et Développement. Seuil, Paris.

Uggla, C., Gurmu, E. and Gibson, M.A., 2018. Are Wives and Daughters Disadvantaged in Polygynous Households? A Case Study of the Arsi Oromo of Ethiopia. Evolution and Human Behavior 39, 160-165.

UNAIDS, 2016a. Global AIDS Update. UNAIDS, Geneva.

UNAIDS, 2016b. AIDS by the Numbers. UNAIDS, Geneva.

Watts, C.H. and May, R.M., 1992. The Influence of Concurrent Partnerships on the Dynamics of HIV/AIDS. Mathematical Biosciences 108, 89-104.

Weisfeld, G.E., Weisfeld, C.C. and Dillon, L.M., 2018. The Psychology of Marriage: An Evolutionary and Cross-Cultural View. Lexington Books, London.

White, D.R. and Burton, M.L., 1988. Causes of Polygyny: Ecology, Economy, Kinship, and Warfare. American Anthropologist 90, 871-887.

WHO, 2012. World Health Statistics 2012. World Health Organization, France.

Young, A. 2019. Channelling Fisher: Randomization Tests and the Statistical Insignificance of Seemingly Significant Experimental Results. Quarterly Journal of Economics $134,557-598$. 
Young, A., 2007. In Sorrow to Bring Forth Children: Fertility amidst the Plague of HIV. Journal of Economic Growth 12, 283-327.

Young, A., 2005. The Gift of the Dying: The Tragedy of AIDS and the Welfare of Future African Generations. Quarterly Journal of Economics 120, 423-466. 


\section{ONLINE APPENDIX}

Table A1: DHS Countries and Waves

\begin{tabular}{lccccc}
\hline Country & DHS Wave & DHS Year & Obs. & Freq. & Cum. \\
\hline Burkina Faso & VI & 2010 & 16542 & 6.79 & 6.79 \\
Burundi & VI & 2010 & 8792 & 3.61 & 10.4 \\
Cameroon & VI & 2011 & 14689 & 6.03 & 24.32 \\
Congo Democratic Repubblic & V & 2007 & 9486 & 3.89 & 14.29 \\
Cote d'Ivoire & VI & 2012 & 9767 & 4.01 & 18.3 \\
Ethiopia & VI & 2011 & 31032 & 12.73 & 37.06 \\
Gabon & VI & 2012 & 11379 & 4.67 & 41.73 \\
Ghana & IV & 2003 & 12030 & 4.94 & 46.66 \\
Guinea & IV & 2005 & 7010 & 2.88 & 49.54 \\
Kenya & V & 2009 & 7017 & 2.88 & 52.42 \\
Lesotho & V & 2009 & 7178 & 2.95 & 60.47 \\
Liberia & V & 2007 & 12456 & 5.11 & 57.53 \\
Malawi & V & 2010 & 14732 & 6.04 & 70.21 \\
Mali & V & 2006 & 9007 & 3.7 & 64.17 \\
Rwanda & VI & 2010 & 13522 & 5.55 & 75.76 \\
Senegal & IV & 2005 & 7993 & 3.28 & 81.82 \\
Sierra Leone & V & 2008 & 6769 & 2.78 & 78.54 \\
Swaziland & V & 2007 & 13244 & 5.43 & 87.25 \\
Zambia & V & 2007 & 11138 & 4.57 & 91.82 \\
Zimbabwe & VI & 2010 & 19924 & 8.18 & 100 \\
\hline
\end{tabular}




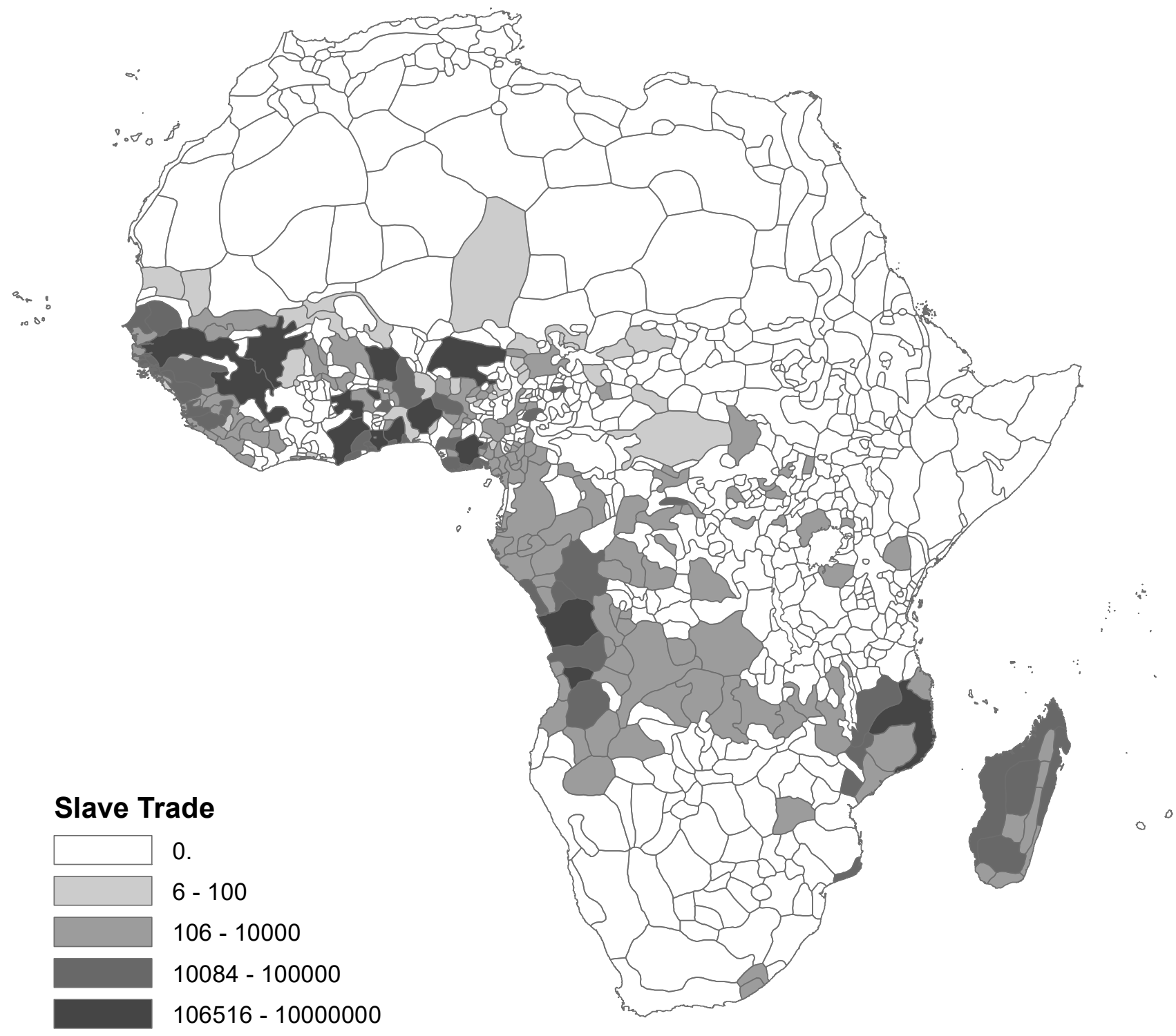

Figure A1: The Geographical Distribution of the Transatlantic Slave Trade by Ethnicity

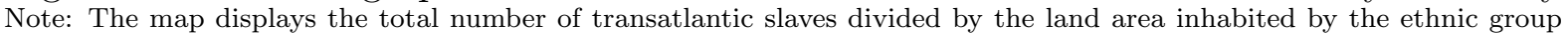
during the nineteenth century. The source is Nunn and Wantchekon (2011). 


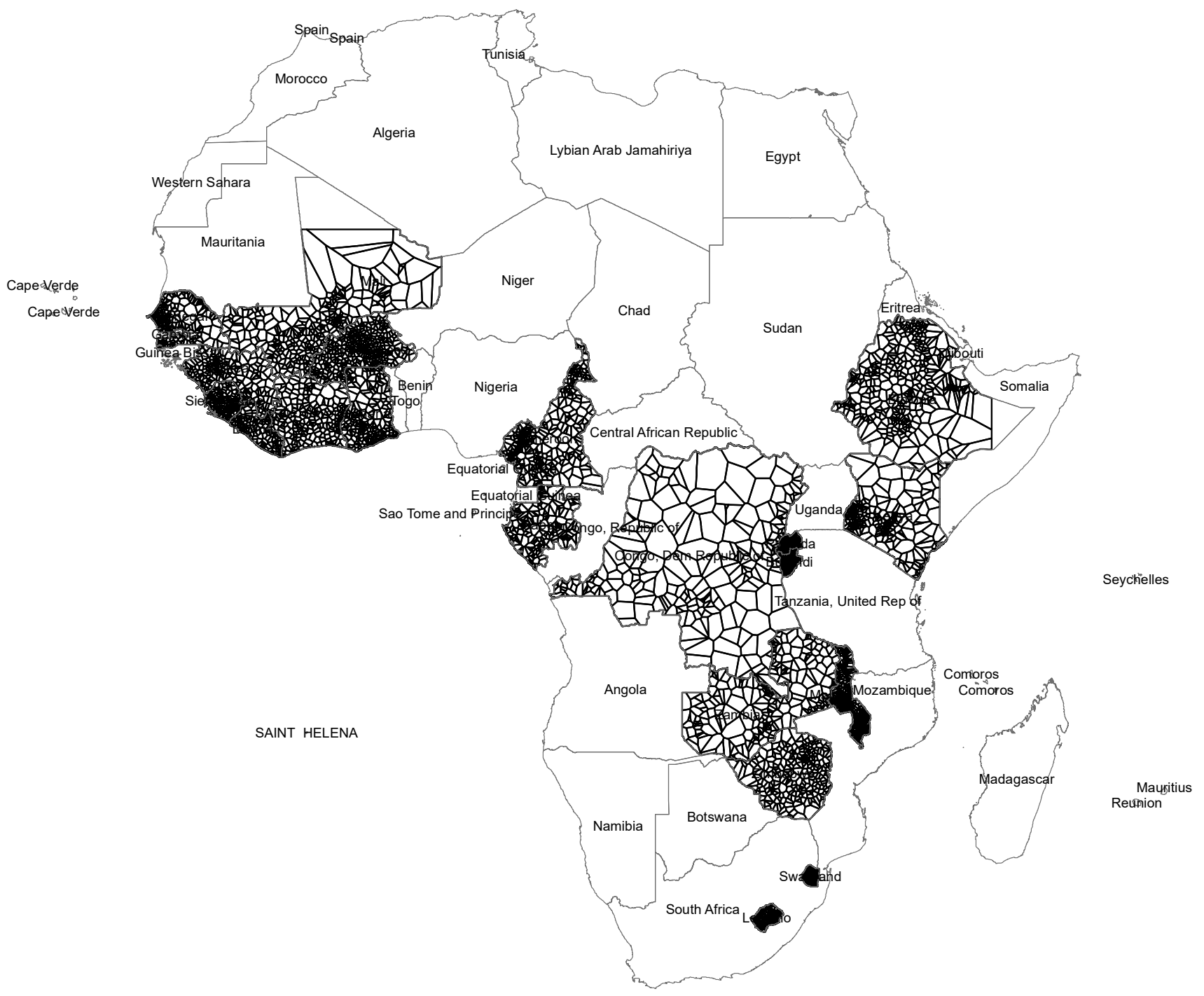

Figure A2: DHS Clusters

Note: GPS Point Coordinates Transformed in Polygons Using a Voronoi Diagram. 
Table A2: Data Description

\begin{tabular}{|c|c|c|}
\hline Variable & Description & Source \\
\hline Year of the Survey & $\begin{array}{l}\text { Categorical Variable for the } \\
\text { Year the Survey Is Conducted - } \\
9 \text { values (hv007) }\end{array}$ & $\begin{array}{l}\text { Demographic and Health Sur- } \\
\text { veys }\end{array}$ \\
\hline HIV & $\begin{array}{l}\text { Dummy Variable for Testing } \\
\text { HIV Positive to Blood Test } \\
\text { (hiv03) }\end{array}$ & $\begin{array}{l}\text { Demographic and Health Sur- } \\
\text { veys }\end{array}$ \\
\hline Number of Wives & $\begin{array}{l}\text { Number of Wives for Men } \\
(\mathrm{mv} 505) \text {, Number of Co-wives } \\
\text { for Women (v505) }\end{array}$ & $\begin{array}{l}\text { Demographic and Health Sur- } \\
\text { veys }\end{array}$ \\
\hline Polygyny & Dummy Variable for Polygyny & $\begin{array}{l}\text { Demographic and Health Sur- } \\
\text { veys }\end{array}$ \\
\hline Co-wife Rank & $\begin{array}{l}\text { Rank among Partner's Wives } \\
\text { (v506) }\end{array}$ & $\begin{array}{l}\text { Demographic and Health Sur- } \\
\text { veys }\end{array}$ \\
\hline Infidelity & $\begin{array}{l}\text { Dummy Variable for Extramar- } \\
\text { ital Sexual Partners in Last } 12 \\
\text { Months (mv766a for Men, v766a } \\
\text { for Women) }\end{array}$ & $\begin{array}{l}\text { Demographic and Health Sur- } \\
\text { veys }\end{array}$ \\
\hline No Co-residence & $\begin{array}{l}\text { Dummy Variable for Partner } \\
\text { Staying Elsewhere (mv504 for } \\
\text { Men, v504 for Women) }\end{array}$ & $\begin{array}{l}\text { Demographic and Health Sur- } \\
\text { veys }\end{array}$ \\
\hline Anemia & $\begin{array}{l}\text { Dummy Variable for Mild, } \\
\text { Moderate, or Severe Anemia } \\
\text { (v457) }\end{array}$ & $\begin{array}{l}\text { Demographic and Health Sur- } \\
\text { veys }\end{array}$ \\
\hline Iodine Deficiency & $\begin{array}{l}\text { Dummy Variable for More than } \\
15 \mathrm{Ppm}(\mathrm{hv} 234)\end{array}$ & $\begin{array}{l}\text { Demographic and Health Sur- } \\
\text { veys }\end{array}$ \\
\hline Only Man Reports Co-wives & $\begin{array}{l}\text { Dummy Variable for Man Re- } \\
\text { porting More than One Wife } \\
\text { and Wife Not Reporting Co- } \\
\text { wives or Not Responding }\end{array}$ & $\begin{array}{l}\text { Demographic and Health Sur- } \\
\text { veys }\end{array}$ \\
\hline HIV Consent Refused & $\begin{array}{l}\text { Dummy Variable for Refusing } \\
\text { Consent to HIV Test (v473a) }\end{array}$ & $\begin{array}{l}\text { Demographic and Health Sur- } \\
\text { veys }\end{array}$ \\
\hline Age & 5-Years Age Groups & $\begin{array}{l}\text { Demographic and Health Sur- } \\
\text { veys }\end{array}$ \\
\hline Sex & $\begin{array}{l}\text { Dummy Variable for Sex - Male, } \\
\text { Female (hv104) }\end{array}$ & $\begin{array}{l}\text { Demographic and Health Sur- } \\
\text { veys }\end{array}$ \\
\hline Marital Status & $\begin{array}{l}\text { Categorical Variable for Mar- } \\
\text { ried - Never, Currently, For- } \\
\text { merly (hv116) }\end{array}$ & $\begin{array}{l}\text { Demographic and Health Sur- } \\
\text { veys }\end{array}$ \\
\hline Education & Education in Years (hv124) & $\begin{array}{l}\text { Demographic and Health Sur- } \\
\text { veys }\end{array}$ \\
\hline Religion & $\begin{array}{l}\text { Categorical Variable for Reli- } \\
\text { gion - } 10 \text { values (mv130 for Men, } \\
\text { v130 for Women) }\end{array}$ & $\begin{array}{l}\text { Demographic and Health Sur- } \\
\text { veys }\end{array}$ \\
\hline Employment & $\begin{array}{l}\text { Categorical Variable for Being } \\
\text { Employed in the Past Year - } \\
\text { Not Employed, In Past Year, } \\
\text { Currently, On Leave (mv731 for } \\
\text { Men, v731 for Women) }\end{array}$ & $\begin{array}{l}\text { Demographic and Health Sur- } \\
\text { veys }\end{array}$ \\
\hline Wealth & $\begin{array}{lll}\begin{array}{l}\text { Household } \\
\text { (hv270) }\end{array} & \text { Wealth } & \text { Index } \\
\end{array}$ & $\begin{array}{l}\text { Demographic and Health Sur- } \\
\text { veys }\end{array}$ \\
\hline Relationship to the Head & $\begin{array}{l}\text { Categorical Variable for the Re- } \\
\text { lation to the Head - } 16 \text { values } \\
\text { (hv101) }\end{array}$ & $\begin{array}{l}\text { Demographic and Health Sur- } \\
\text { veys }\end{array}$ \\
\hline
\end{tabular}


Table A2: Data Description - Continued

\begin{tabular}{|c|c|c|}
\hline Age of the Head & $\begin{array}{l}\text { Age of the Household Head in } \\
\text { Years (hv220) }\end{array}$ & $\begin{array}{l}\text { Demographic and Health Sur- } \\
\text { veys }\end{array}$ \\
\hline Sex of the Head & $\begin{array}{l}\text { Dummy Variable for Sex of the } \\
\text { Household Head - Male, Female } \\
\text { (hv219) }\end{array}$ & $\begin{array}{l}\text { Demographic and Health Sur- } \\
\text { veys }\end{array}$ \\
\hline Number of Household Members & $\begin{array}{l}\text { Number of Household Members } \\
\text { (hv009) }\end{array}$ & $\begin{array}{l}\text { Demographic and Health Sur- } \\
\text { veys }\end{array}$ \\
\hline Clusters & $\begin{array}{l}\text { Voronoi Transformation of DHS } \\
\text { GPS Coordinates }\end{array}$ & $\begin{array}{l}\text { Demographic and Health Sur- } \\
\text { veys }\end{array}$ \\
\hline Longitude & DHS Coordinates & $\begin{array}{l}\text { Demographic and Health Sur- } \\
\text { veys }\end{array}$ \\
\hline $\begin{array}{l}\text { Slave Trades and Ethnic Land } \\
\text { Areas }\end{array}$ & $\begin{array}{lrr}\text { Number } & \text { of } & \text { Transat- } \\
\text { lantic/Indian } & \text { Ocean } & \text { Slaves } \\
\text { over Ethnic Land Area } & \end{array}$ & Nunn and Wantchekon (2011) \\
\hline Regional GDP 2000 & $\begin{array}{l}\text { Spatial Data on Total Economic } \\
\text { Activity }\end{array}$ & $\begin{array}{l}\text { National Geophysical Data } \\
\text { Center (Ghosh et al., 2010) }\end{array}$ \\
\hline Population Density 2000 & $\begin{array}{l}\text { Spatial Data on } \text { Population } \\
\text { Density }\end{array}$ & $\begin{array}{l}\text { Gridded Population of the } \\
\text { World (SEDAC/CIESIN) }\end{array}$ \\
\hline Population Density 1800 & $\begin{array}{l}\text { Spatial Data on Population } \\
\text { Density }\end{array}$ & $\begin{array}{l}\text { HYDE (History Database of the } \\
\text { Global Environment) }\end{array}$ \\
\hline Rugged Terrain & DEM Terrain Analysis in QGIS & $\begin{array}{ll}\text { Harmonized World } & \text { Soil } \\
\text { Database (IIASA) } & \end{array}$ \\
\hline Mean Elevation & DEM Terrain Analysis in QGIS & $\begin{array}{ll}\text { Harmonized World } & \text { Soil } \\
\text { Database (IIASA) } & \end{array}$ \\
\hline Water Basins & Share of Inland Water Bodies & $\begin{array}{l}\text { FAO GAEZ (Land and Water } \\
\text { Resources) }\end{array}$ \\
\hline Rainfall & $\begin{array}{ll}\begin{array}{l}\text { Total Annual } \\
(1960-2000)\end{array} & \text { Precipitation } \\
\end{array}$ & $\begin{array}{l}\text { FAO GAEZ (Agro-climatic Re- } \\
\text { sources Moisture Regimes) }\end{array}$ \\
\hline Temperature & $\begin{array}{l}\text { Annual Temperature }(1960- \\
2000)\end{array}$ & $\begin{array}{l}\text { FAO GAEZ (Agro-climatic Re- } \\
\text { sources Thermal Regimes) }\end{array}$ \\
\hline Soil PH & Natural Soil Acidity & $\begin{array}{l}\text { FAO GAEZ (Agricultural Suit- } \\
\text { ability and Potential Yields) }\end{array}$ \\
\hline Soil Nutrients Availability & Soil Classification & $\begin{array}{l}\text { FAO GAEZ (Agricultural Suit- } \\
\text { ability and Potential Yields) }\end{array}$ \\
\hline Growing Season & Length of the Growing Season & $\begin{array}{l}\text { FAO GAEZ (Agro-climatic Re- } \\
\text { sources Agro-Ecological Zones) }\end{array}$ \\
\hline Colonial Routes & $\begin{array}{l}\text { Dummy Variable for whether } \\
\text { the Cluster is Crossed by a } \\
\text { Colonial Route }\end{array}$ & Nunn and Wantchekon (2011) \\
\hline Colonial Railways & $\begin{array}{l}\text { Dummy Variable for whether } \\
\text { the Cluster is Crossed by a } \\
\text { Colonial Railway }\end{array}$ & Nunn and Wantchekon (2011) \\
\hline Christian Missions & Number of Christian Missions & Nunn $(2010)$ \\
\hline Distance from the Coast & $\begin{array}{l}\text { Centroid Distance of the Cluster } \\
\text { from the Coast (in km) }\end{array}$ & $\begin{array}{l}\text { NASA Ocean Biology Process- } \\
\text { ing Group }\end{array}$ \\
\hline $\begin{array}{l}\text { Norms of Premarital Sexual Be- } \\
\text { havior for Girls }\end{array}$ & $\begin{array}{l}\text { Categorical Variable - Allowed, } \\
\text { Early Marriage, Free, Virgin- } \\
\text { ity, Weakly Censored, Prohib- } \\
\text { ited (v78) }\end{array}$ & $\begin{array}{l}\text { Ethnographic Atlas (Murdock, } \\
\text { 1967) }\end{array}$ \\
\hline Mode of Marriage & $\begin{array}{l}\text { Categorical Variable - No Con- } \\
\text { sideration, Bride Price, Bride } \\
\text { Service, Dowry, Female Ex- } \\
\text { change, Token Bride (v6) }\end{array}$ & $\begin{array}{l}\text { Ethnographic Atlas (Murdock, } \\
\text { 1967) }\end{array}$ \\
\hline
\end{tabular}


Table A3: Descriptive Statistics - Full Sample

\begin{tabular}{|c|c|c|c|c|c|}
\hline & count & mean & $\mathrm{sd}$ & $\min$ & $\max$ \\
\hline $\mathrm{HIV}$ & 236254 & 0.059 & 0.236 & 0.000 & 1.000 \\
\hline Number of Wives & 131712 & 1.253 & 0.607 & 1.000 & 17.000 \\
\hline Polygyny & 131712 & 0.188 & 0.391 & 0.000 & 1.000 \\
\hline Co-wife Rank & 17472 & 1.725 & 0.744 & 1.000 & 13.000 \\
\hline Infidelity - Women & 122504 & 0.131 & 0.338 & 0.000 & 1.000 \\
\hline Infidelity - Men & 105363 & 0.260 & 0.439 & 0.000 & 1.000 \\
\hline No Co-residence & 124418 & 0.155 & 0.362 & 0.000 & 1.000 \\
\hline Year of Survey & 243707 & 2007.865 & 2.988 & 2003.000 & 2012.000 \\
\hline Age & 228971 & 3.503 & 2.122 & 1.000 & 9.000 \\
\hline Sex & 243707 & 1.532 & 0.499 & 1.000 & 2.000 \\
\hline Marital Status & 202269 & 0.712 & 0.582 & 0.000 & 2.000 \\
\hline Education & 242007 & 1.375 & 3.298 & 0.000 & 21.000 \\
\hline Religion & 227107 & 2.521 & 1.845 & 0.000 & 10.000 \\
\hline Employment & 228669 & 1.375 & 0.905 & 0.000 & 3.000 \\
\hline Wealth & 243707 & 3.100 & 1.451 & 1.000 & 5.000 \\
\hline Relationship to the Head & 243663 & 3.209 & 3.115 & 1.000 & 16.000 \\
\hline Age of the Head & 243643 & 44.045 & 14.232 & 13.000 & 95.000 \\
\hline Sex of the Head & 243707 & 1.234 & 0.424 & 1.000 & 2.000 \\
\hline Number of Household Members & 243707 & 6.495 & 3.971 & 1.000 & 74.000 \\
\hline Anemia & 97174 & 0.370 & 0.483 & 0.000 & 1.000 \\
\hline Iodine Deficiency & 92659 & 0.646 & 0.478 & 0.000 & 1.000 \\
\hline Slave Trade - Transatlantic & 233853 & 0.642 & 2.968 & 0.000 & 37.703 \\
\hline Slave Trade - Indian Ocean & 233853 & 0.025 & 0.287 & 0.000 & 9.803 \\
\hline Number of Slaves - Transatlantic & 233853 & 34229.121 & 189573.466 & 0.000 & 3838953.000 \\
\hline Number of Slaves - Indian Ocean & 233853 & 1380.376 & 14268.212 & 0.000 & 171212.000 \\
\hline Ethnic Land & 233853 & 48976.329 & 50135.324 & 996.383 & 317587.313 \\
\hline Regional GDP 2000 - Night Lights & 234119 & 2.872 & 10.697 & 0.000 & 160.995 \\
\hline Population Density 2000 & 234119 & 769.918 & 2924.185 & 0.000 & 57665.898 \\
\hline Population Density 1800 & 234119 & 17.562 & 55.072 & 0.000 & 811.664 \\
\hline Rugged Terrain & 234119 & 92.146 & 93.171 & 0.000 & 665.251 \\
\hline Mean Elevation & 233853 & 612.360 & 28819.979 & 0.000 & 1507447.500 \\
\hline Water Basins & 234119 & 2.717 & 10.881 & 0.000 & 100.000 \\
\hline Rainfall & 234119 & 1256.772 & 639.886 & 0.000 & 3274.250 \\
\hline Temperature & 234119 & 22.923 & 4.262 & 0.000 & 30.160 \\
\hline Soil PH & 234119 & 27.610 & 9.203 & 0.000 & 97.111 \\
\hline Soil Nutrients Availability & 234119 & 1.983 & 0.919 & 0.000 & 7.000 \\
\hline Growing Season & 234119 & 212.660 & 74.409 & 0.000 & 365.095 \\
\hline Colonial Routes & 243707 & 0.081 & 0.273 & 0.000 & 1.000 \\
\hline Colonial Railways & 243707 & 0.036 & 0.185 & 0.000 & 1.000 \\
\hline Number of Christian Missions & 233853 & 0.074 & 0.428 & 0.000 & 15.000 \\
\hline Distance from the Coast & 233853 & 505.131 & 385.366 & 0.000 & 1805.101 \\
\hline Longitude & 243707 & 16.212 & 18.480 & -17.470 & 43.790 \\
\hline
\end{tabular}


Table A4: Descriptive Statistics - Monogamy Sample

\begin{tabular}{|c|c|c|c|c|c|}
\hline & count & mean & $\mathrm{sd}$ & $\min$ & $\max$ \\
\hline HIV & 105031 & 0.059 & 0.235 & 0.000 & 1.000 \\
\hline Number of Wives & 106982 & 1.000 & 0.000 & 1.000 & 1.000 \\
\hline Polygyny & 106982 & 0.000 & 0.000 & 0.000 & 0.000 \\
\hline Co-wife Rank & 0 & & . & & . \\
\hline Infidelity - Women & 56570 & 0.028 & 0.165 & 0.000 & 1.000 \\
\hline Infidelity - Men & 49863 & 0.144 & 0.351 & 0.000 & 1.000 \\
\hline No Co-residence & 98231 & 0.140 & 0.347 & 0.000 & 1.000 \\
\hline Year of Survey & 106982 & 2007.851 & 3.042 & 2003.000 & 2012.000 \\
\hline Age & 106982 & 4.312 & 1.927 & 1.000 & 9.000 \\
\hline Sex & 106982 & 1.531 & 0.499 & 1.000 & 2.000 \\
\hline Marital Status & 91399 & 0.989 & 0.151 & 0.000 & 2.000 \\
\hline Education & 106294 & 0.130 & 1.163 & 0.000 & 20.000 \\
\hline Religion & 106112 & 2.513 & 1.812 & 0.000 & 10.000 \\
\hline Employment & 106888 & 1.540 & 0.821 & 0.000 & 3.000 \\
\hline Wealth & 106982 & 3.011 & 1.444 & 1.000 & 5.000 \\
\hline Relationship to the Head & 106973 & 2.066 & 2.038 & 1.000 & 16.000 \\
\hline Age of the Head & 106958 & 39.973 & 12.402 & 14.000 & 95.000 \\
\hline Sex of the Head & 106982 & 1.116 & 0.321 & 1.000 & 2.000 \\
\hline Number of Household Members & 106982 & 5.815 & 3.350 & 1.000 & 74.000 \\
\hline Anemia & 44284 & 0.364 & 0.481 & 0.000 & 1.000 \\
\hline Iodine Deficiency & 36569 & 0.638 & 0.481 & 0.000 & 1.000 \\
\hline Slave Trade - Transatlantic & 102592 & 0.627 & 2.879 & 0.000 & 37.703 \\
\hline Slave Trade - Indian Ocean & 102592 & 0.029 & 0.292 & 0.000 & 9.803 \\
\hline Number of Slaves - Transatlantic & 102592 & 32769.180 & 175634.722 & 0.000 & 3838953 \\
\hline Number of Slaves - Indian Ocean & 102592 & 1650.794 & 15652.604 & 0.000 & 171212 \\
\hline Ethnic Land & 102592 & 48567.267 & 50410.713 & 996.383 & 317587.313 \\
\hline Regional GDP 2000 - Night Lights & 102724 & 2.570 & 10.328 & 0.000 & 160.995 \\
\hline Population Density 2000 & 102724 & 696.949 & 2761.126 & 0.000 & 57665.898 \\
\hline Population Density 1800 & 102724 & 16.831 & 51.394 & 0.000 & 811.664 \\
\hline Rugged Terrain & 102724 & 91.374 & 93.449 & 0.000 & 665.251 \\
\hline Mean Elevation & 102592 & 505.826 & 26117.193 & 0.000 & 1507447.500 \\
\hline Water Basins & 102724 & 2.790 & 11.173 & 0.000 & 100.000 \\
\hline Rainfall & 102724 & 1278.525 & 642.502 & 0.000 & 3274.250 \\
\hline Temperature & 102724 & 23.112 & 4.028 & 0.000 & 30.160 \\
\hline Soil PH & 102724 & 27.535 & 9.410 & 0.000 & 97.111 \\
\hline Soil Nutrients Availability & 102724 & 1.990 & 0.920 & 0.000 & 7.000 \\
\hline Growing Season & 102724 & 214.397 & 75.500 & 0.000 & 365.095 \\
\hline Colonial Routes & 106982 & 0.086 & 0.281 & 0.000 & 1.000 \\
\hline Colonial Railways & 106982 & 0.035 & 0.185 & 0.000 & 1.000 \\
\hline Number of Christian Missions & 102592 & 0.076 & 0.432 & 0.000 & 15.000 \\
\hline Distance from the Coast & 102592 & 533.731 & 388.700 & 0.000 & 1805.101 \\
\hline Longitude & 106982 & 16.537 & 18.672 & -17.470 & 43.790 \\
\hline
\end{tabular}


Table A5: Descriptive Statistics - Polygyny Sample

\begin{tabular}{|c|c|c|c|c|c|}
\hline & count & mean & $\mathrm{sd}$ & $\min$ & $\max$ \\
\hline $\mathrm{HIV}$ & 24408 & 0.041 & 0.199 & 0.000 & 1.000 \\
\hline Number of Wives & 24730 & 2.348 & 0.697 & 2.000 & 17.000 \\
\hline Polygyny & 24730 & 1.000 & 0.000 & 1.000 & 1.000 \\
\hline Co-wife Rank & 17472 & 1.725 & 0.744 & 1.000 & 13.000 \\
\hline Infidelity - Women & 17421 & 0.032 & 0.175 & 0.000 & 1.000 \\
\hline Infidelity - Men & 7151 & 0.139 & 0.346 & 0.000 & 1.000 \\
\hline No Co-residence & 22054 & 0.179 & 0.384 & 0.000 & 1.000 \\
\hline Year of Survey & 24730 & 2007.663 & 2.871 & 2003.000 & 2012.000 \\
\hline Age & 24730 & 4.843 & 1.925 & 1.000 & 9.000 \\
\hline Sex & 24730 & 1.708 & 0.455 & 1.000 & 2.000 \\
\hline Marital Status & 17078 & 1.002 & 0.173 & 0.000 & 2.000 \\
\hline Education & 24640 & 0.051 & 0.704 & 0.000 & 16.000 \\
\hline Religion & 24515 & 2.306 & 1.770 & 0.000 & 10.000 \\
\hline Employment & 24708 & 1.570 & 0.808 & 0.000 & 3.000 \\
\hline Wealth & 24730 & 2.638 & 1.335 & 1.000 & 5.000 \\
\hline Relationship to the Head & 24729 & 2.128 & 1.992 & 1.000 & 14.000 \\
\hline Age of the Head & 24718 & 45.413 & 12.534 & 15.000 & 95.000 \\
\hline Sex of the Head & 24730 & 1.162 & 0.368 & 1.000 & 2.000 \\
\hline Number of Household Members & 24730 & 8.426 & 4.776 & 1.000 & 74.000 \\
\hline Anemia & 14447 & 0.483 & 0.500 & 0.000 & 1.000 \\
\hline Iodine Deficiency & 10186 & 0.571 & 0.495 & 0.000 & 1.000 \\
\hline Slave Trade - Transatlantic & 23624 & 0.875 & 3.195 & 0.000 & 37.703 \\
\hline Slave Trade - Indian Ocean & 23624 & 0.022 & 0.295 & 0.000 & 9.803 \\
\hline Number of Slaves - Transatlantic & 23624 & 58333.560 & 203129.106 & 0.000 & 3838953 \\
\hline Number of Slaves - Indian Ocean & 23624 & 1089.908 & 12554.040 & 0.000 & 171212 \\
\hline Ethnic Land & 23624 & 54509.082 & 63387.776 & 996.383 & 317587.313 \\
\hline Regional GDP 2000 - Night Lights & 23644 & 1.259 & 7.266 & 0.000 & 160.995 \\
\hline Population Density 2000 & 23644 & 321.036 & 1853.265 & 0.000 & 57665.898 \\
\hline Population Density 1800 & 23644 & 11.500 & 46.140 & 0.000 & 811.664 \\
\hline Rugged Terrain & 23644 & 61.497 & 69.644 & 0.000 & 557.651 \\
\hline Mean Elevation & 23624 & 59.737 & 9167.591 & 0.000 & 1409066.375 \\
\hline Water Basins & 23644 & 2.036 & 9.297 & 0.000 & 100.000 \\
\hline Rainfall & 23644 & 1266.392 & 665.529 & 0.000 & 3274.250 \\
\hline Temperature & 23644 & 25.412 & 3.363 & 0.000 & 30.160 \\
\hline Soil PH & 23644 & 28.062 & 8.750 & 0.000 & 97.000 \\
\hline Soil Nutrients Availability & 23644 & 1.886 & 0.884 & 0.000 & 7.000 \\
\hline Growing Season & 23644 & 196.678 & 73.632 & 0.000 & 365.000 \\
\hline Colonial Routes & 24730 & 0.128 & 0.334 & 0.000 & 1.000 \\
\hline Colonial Railways & 24730 & 0.032 & 0.176 & 0.000 & 1.000 \\
\hline Number of Christian Missions & 23624 & 0.062 & 0.399 & 0.000 & 15.000 \\
\hline Distance from the Coast & 23624 & 515.355 & 362.398 & 0.000 & 1805.101 \\
\hline Longitude & 24730 & 5.717 & 17.847 & -17.467 & 43.790 \\
\hline
\end{tabular}


Table A6: Slave vs Non-Slave Clusters: Differences in Mean

\begin{tabular}{lccccccc}
\hline & \multicolumn{7}{c}{ Panel A - DHS Cluster Level } \\
\hline & $(1)$ & $(2)$ & $(3)$ & $(4)$ & $(5)$ & $(6)$ & \\
& GDP 2000 & Pop. 2000 & Pop. 1800 & Routes & Railways & Dist. Coast & \\
\hline Treatment & 0.0928 & 0.150 & 0.0786 & 0.0108 & 0.00747 & -279.1 & \\
& {$[0.115]$} & {$[0.0979]$} & {$[0.162]$} & {$[0.0258]$} & {$[0.0130]$} & {$[96.75]$} & \\
\hline Adj. R-sq. & 0.002 & 0.005 & 0.001 & 0.000 & 0.000 & 0.128 & \\
Observations & 8220 & 8220 & 8220 & 8220 & 8220 & 8220 & \\
Ethnicities & 343 & 343 & 343 & 343 & 343 & 343 & \\
\hline \hline & & & Panel B - Individual Level & & \\
\hline & $(1)$ & $(2)$ & $(3)$ & $(4)$ & $(5)$ & $(6)$ & $(7)$ \\
& Sex Head & Sex & Age Head & Age & Education & Wealth & Polygyny \\
\hline Tretament & -0.0641 & 0.00219 & 1.292 & 0.143 & -0.00310 & -0.00818 & 0.0953 \\
& $(0.00448)$ & $(0.00198)$ & $(0.144)$ & $(0.0118)$ & $(0.0274)$ & $(0.0289)$ & $(0.00485)$ \\
& {$[0.0291]$} & {$[0.00498]$} & {$[0.770]$} & {$[0.0413]$} & {$[0.101]$} & {$[0.107]$} & {$[0.0271]$} \\
\hline \hline Adj. R-sq. & 0.006 & 0.000 & 0.002 & 0.001 & -0.000 & 0.000 & 0.015 \\
Observations & 233853 & 233853 & 233853 & 219713 & 232193 & 233853 & 126216 \\
DHS Clusters & 8220 & 8220 & 8220 & 8220 & 8220 & 8220 & 8204 \\
Ethnicities & 343 & 343 & 343 & 343 & 343 & 343 & 343 \\
\hline
\end{tabular}

Note: OLS estimates. Treatment is a dummy variable that is equal to one if in the cluster the number of transatlantic slaves is larger than zero, and zero otherwise. Clustered robust standard errors at an ethnicity level in square brackets. Clustered robust standard errors at a DHS cluster level in parentheses. 
Table A7: HIV, the Slave Trade, and Other Covariates

\begin{tabular}{|c|c|c|c|}
\hline & \multicolumn{3}{|c|}{$\mathrm{HIV}$} \\
\hline & Coef. & S.E. - DHS Cluster & S.E. - Ethnicity \\
\hline Slave Trade & 0.00290 & 0.000810 & 0.00236 \\
\hline Regional GDP 2000 & -0.000807 & 0.000870 & 0.00124 \\
\hline Population Density 2000 & 0.00143 & 0.000838 & 0.00107 \\
\hline Population Density 1800 & 0.00156 & 0.00102 & 0.00137 \\
\hline Rugged Terrain & -0.00114 & 0.00118 & 0.00135 \\
\hline Mean Elevation & -0.000348 & 0.000209 & 0.0000503 \\
\hline Water Basins & 0.000479 & 0.00115 & 0.00117 \\
\hline Rainfall & -0.00974 & 0.00196 & 0.00394 \\
\hline Temperature & 0.00233 & 0.00191 & 0.00369 \\
\hline Soil PH & 0.00112 & 0.00135 & 0.00170 \\
\hline Soil Nutrients Availability & 0.000477 & 0.00133 & 0.00244 \\
\hline Growing Season & 0.00803 & 0.00203 & 0.00532 \\
\hline Colonial Routes & -0.00933 & 0.00355 & 0.00488 \\
\hline Colonial Railways & 0.0185 & 0.00696 & 0.00705 \\
\hline Christian Missions & -0.000261 & 0.000554 & 0.000555 \\
\hline Age & 0.00689 & 0.000568 & 0.00122 \\
\hline Sex & 0.0312 & 0.00179 & 0.00724 \\
\hline Currently Married & 0.00883 & 0.00296 & 0.00479 \\
\hline Formerly/Ever Married & 0.112 & 0.00525 & 0.0163 \\
\hline Education & -0.00395 & 0.000224 & 0.00129 \\
\hline Employed Past Year & 0.00789 & 0.00276 & 0.00515 \\
\hline Employed Currently & 0.00632 & 0.00197 & 0.00362 \\
\hline Employed On Leave & 0.0294 & 0.00785 & 0.00897 \\
\hline Wealth & 0.0101 & 0.000702 & 0.00142 \\
\hline Age of the Head & 0.0000964 & 0.0000704 & 0.0000858 \\
\hline Sex of the Head & 0.00600 & 0.00198 & 0.00341 \\
\hline Household Members & -0.00280 & 0.000292 & 0.000606 \\
\hline Other Controls & Yes & & \\
\hline Country FE & Yes & & \\
\hline Adj. R-sq. & 0.122 & & \\
\hline Observations & 178605 & & \\
\hline DHS Clusters & 6750 & & \\
\hline Ethnicities & 308 & & \\
\hline Sample & Full & & \\
\hline
\end{tabular}

Note: OLS estimates, corresponding to those in Table 1, Model 4. HIV is a dummy variable for testing positive to HIV. Slave Trade is the natural log of 0.01 plus transatlantic slave exports normalized by ethnic land area. The omitted category for Sex is Male, for Married is Never Married, and for Employed is Not Employed. The other controls include: Year of the Survey, Relationship to the Head (a set of 16 dummy variables), and Religion (a set of 10 dummy variables). 
Table A8: HIV and the Slave Trade - Unweighted Estimates and Spatial Clustering

\begin{tabular}{|c|c|c|c|c|c|c|}
\hline & \multicolumn{6}{|c|}{ HIV } \\
\hline & (1) & $(2)$ & (3) & (4) & (5) & (6) \\
\hline \multirow[t]{6}{*}{ Slave Trade } & 0.00186 & 0.00228 & 0.00134 & 0.00266 & 0.00364 & 0.00162 \\
\hline & $(0.000363)$ & $(0.000472)$ & $(0.000382)$ & $(0.000648)$ & $(0.000843)$ & $(0.000675)$ \\
\hline & {$[0.00131]$} & {$[0.00148]$} & {$[0.00110]$} & {$[0.00230]$} & {$[0.00253]$} & {$[0.00204]$} \\
\hline & $\{0.000745\}$ & $\{0.000916\}$ & $\{0.000626\}$ & $\{0.00132\}$ & $\{0.00157\}$ & $\{0.00115\}$ \\
\hline & $\{0.00110\}$ & $\{0.00128\}$ & $\{0.000915\}$ & $\{0.00191\}$ & $\{0.00127\}$ & $\{0.00168\}$ \\
\hline & $\{0.00111\}$ & $\{0.00128\}$ & $\{0.000927\}$ & $\{0.00191\}$ & $\{0.00214\}$ & $\{0.00172\}$ \\
\hline Controls & No & No & No & Yes & Yes & Yes \\
\hline Country FE & Yes & Yes & Yes & Yes & Yes & Yes \\
\hline Adj. R-sq. & 0.072 & 0.084 & 0.059 & 0.120 & 0.134 & 0.096 \\
\hline Observations & 226742 & 121530 & 105212 & 178605 & 95604 & 83001 \\
\hline Sample & Full & Women & Men & Full & Women & Men \\
\hline
\end{tabular}

Note: Unweighted OLS estimates. HIV is a dummy variable for testing positive to HIV. Slave Trade is the natural log of 0.01 plus transatlantic slave exports normalized by ethnic land area. Clustered robust standard errors at a DHS cluster level in parentheses. Clustered robust standard errors at an ethnicity level in square brackets. Three variants of Conley (1999) standard errors in curly brackets, constructed assuming a window with weights equal to one for observations less than 50 , 150, and $250 \mathrm{~km}$ apart, and zero for observations further apart. In Models 4-6 the controls include: Regional GDP 2000, Population Density 2000, Population Density 1800, Rugged Terrain, Mean Elevation, Water Basins, Rainfall, Temperature, Soil PH, Soil Nutrients Availability, Growing Season, Colonial Routes, Colonial Railways, Christian Missions, Year of the Survey, Age, Sex, Marital Status, Education, Religion, Employment, Wealth, Relationship to the Head, Age of the Household Head, Sex of the Household Head, and Number of Household Members. Sex is dropped from Models 2, 3, 5 and 6.

Table A9: Underreporting of HIV and Polygyny

(1)

HIV Consent Refused

\begin{tabular}{lcc}
\hline Distance from Coast & -0.00156 & -0.00344 \\
& $(0.00645)$ & $(0.000905)$ \\
& {$[0.0331]$} & {$[0.00222]$} \\
Controls & No & No \\
Country FE & No & No \\
\hline Adj. R-sq. & -0.000 & 0.000 \\
Observations & 108320 & 44286 \\
DHS Clusters & 7170 & 7894 \\
Ethnicities & 319 & 343 \\
Sample & Women & Women \\
\hline
\end{tabular}

Note: OLS estimates. HIV Consent Refused and Only Man Reports Co-wives are dummy variables. Distance from Coast is the centroid distance of a DHS cluster from the coast. Clustered robust standard errors at a DHS cluster level in parentheses. Clustered robust standard errors at an ethnicity level in square brackets. 
Table A10: HIV and the Slave Trade - 2SLS Estimates

\begin{tabular}{lccc}
\hline & $(1)$ & Second Stage: HIV & $(3)$ \\
\hline Slave Trade & 0.00372 & 0.00656 & 0.00106 \\
& $(0.00210)$ & $(0.00279)$ & $(0.00225)$ \\
& {$[0.00463]$} & {$[0.00519]$} & {$[0.00442]$} \\
Controls & Yes & Yes & Yes \\
Country FE & Yes & Yes & Yes \\
\hline Adj. R-sq. & 0.000 & 0.000 & 0.000 \\
Observations & 178605 & 95604 & 83001 \\
DHS Clusters & 6750 & 6744 & 6746 \\
Ethnicities & 308 & 308 & 308 \\
Sample & Full & Women & Men \\
\hline \hline
\end{tabular}

\begin{tabular}{lccc}
\hline \hline & \multicolumn{3}{c}{ First Stage: Slave Trade } \\
\hline Distance from Coast & -0.780 & -0.775 & -0.786 \\
& $(0.0427)$ & $(0.0431)$ & $(0.0433)$ \\
& {$[0.185]$} & {$[0.183]$} & {$[0.186]$} \\
\hline First St. F Stat. DHS Cl. & 333.23 & 323.45 & 329.73 \\
First St. F Stat. Ethnic Cl. & 17.83 & 17.87 & 17.79 \\
Anderson LR Stat. & 18286.79 & 9622.31 & 8679.86 \\
Cragg Donald F Stat. & 19255.63 & 10123.10 & 9149.85 \\
Stock and Yogo Crit. Val. & 16.38 & 16.38 & 16.38 \\
\hline
\end{tabular}

Note: 2SLS Estimates. HIV is a dummy variable for testing positive to HIV. Slave Trade is the natural log of 0.01 plus transatlantic slave exports normalized by ethnic land area. Distance from Coast is the centroid distance of a DHS cluster from the coast. Clustered robust standard errors at a DHS cluster level in parentheses. Clustered robust standard errors at an ethnicity level in square brackets. The controls include: Regional GDP 2000, Population Density 2000, Population Density 1800, Rugged Terrain, Mean Elevation, Water Basins, Rainfall, Temperature, Soil PH, Soil Nutrients Availability, Growing Season, Colonial Routes, Colonial Railways, Christian Missions, Year of the Survey, Age, Sex, Marital Status, Education, Religion, Employment, Wealth, Relationship to the Head, Age of the Household Head, Sex of the Household Head, and Number of Household Members. Sex is dropped from Models 2, 3, 5 and 6. 
Table A11: Geographical Heterogeneity

\begin{tabular}{lccccc}
\hline & $(1)$ & $(2)$ & $(3)$ & $(4)$ & $(5)$ \\
\hline Slave Trade - Transatlantic & 0.00278 & 0.00275 & 0.00408 & 0.00311 & 0.00453 \\
& $(0.000789)$ & $(0.000831)$ & $(0.00109)$ & $(0.000809)$ & $(0.00106)$ \\
& {$[0.00231]$} & {$[0.00250]$} & {$[0.00293]$} & {$[0.00211]$} & {$[0.00253]$} \\
Slave Trade - Indian Ocean & 0.00199 & & & & \\
& $(0.00203)$ & & & & \\
& {$[0.00524]$} & & & Yes & Yes \\
Controls & Yes & Yes & Yes & Yes & Yes \\
Country FE & Yes & Yes & Yes & 0.054 & 0.063 \\
\hline Adj. R-sq. & 0.122 & 0.122 & 0.137 & 85511 & 45017 \\
Observations & 178605 & 178605 & 95604 & 3541 & 3539 \\
DHS Clusters & 6750 & 6750 & 6744 & 206 & 206 \\
Ethnicities & 308 & 308 & 308 & Transatlantic & Transatlantic \\
Sample & Full & Full & Women & Women \\
\hline
\end{tabular}

Note: OLS estimates. HIV is a dummy variable for testing positive to HIV. Slave Trade - Transatlantic is the natural log of 0.01 plus transatlantic slave exports normalized by ethnic land area. Slave Trade - Indian Ocean is the natural log of 0.01 plus Indian Ocean slave exports normalized by ethnic land area. Clustered robust standard errors at a DHS cluster level in parentheses. Clustered robust standard errors at an ethnicity level in square brackets. The controls include: Regional GDP 2000, Population Density 2000, Population Density 1800, Rugged Terrain, Mean Elevation, Water Basins, Rainfall, Temperature, Soil PH, Soil Nutrients Availability, Growing Season, Colonial Routes, Colonial Railways, Christian Missions, Year of the Survey, Age, Sex, Marital Status, Education, Religion, Employment, Wealth, Relationship to the Head, Age of the Household Head, Sex of the Household Head, and Number of Household Members. Models 2 and 3 also include Longitude. Sex is dropped from Models 3 and 5.

Table A12: Not Sexually Transmitted Diseases and the Slave Trade

\begin{tabular}{lcc}
\hline & $(1)$ & $(2)$ \\
& Anemia & Iodine Deficiency \\
\hline Slave Trade & 0.00231 & -0.000891 \\
& $(0.00252)$ & $(0.00448)$ \\
Controls & {$[0.00346]$} & {$[0.00567]$} \\
Country FE & Yes & Yes \\
\hline Adj. R-sq. & Yes & Yes \\
Observations & 0.112 & 0.129 \\
DHS Clusters & 73361 & 54197 \\
Ethnicities & 5160 & 2811 \\
Sample & 208 & 111 \\
\hline
\end{tabular}

Note: OLS estimates. Anemia and Iodine Deficiency are dummy variables. Slave Trade is the natural log of 0.01 plus transatlantic slave exports normalized by ethnic land area. Clustered robust standard errors at a DHS cluster level in parentheses. Clustered robust standard errors at an ethnicity level in square brackets. The controls include: Regional GDP 2000, Population Density 2000, Population Density 1800, Rugged Terrain, Mean Elevation, Water Basins, Rainfall, Temperature, Soil PH, Soil Nutrients Availability, Growing Season, Colonial Routes, Colonial Railways, Christian Missions, Year of the Survey, Age, Marital Status, Education, Religion, Employment, Wealth, Relationship to the Head, Age of the Household Head, Sex of the Household Head, and Number of Household Members. 
Table A13: HIV and the Slave Trade by Age Cohort

\begin{tabular}{lcccc}
\hline & & & HIV & \\
& $(1)$ & $(2)$ & $(3)$ & $(4)$ \\
\hline Slave Trade & 0.00113 & 0.00227 & 0.00337 & 0.00400 \\
& $(0.000769)$ & $(0.00116)$ & $(0.00157)$ & $(0.00213)$ \\
& {$[0.000864]$} & {$[0.00198]$} & {$[0.00374]$} & {$[0.00355]$} \\
Controls & Yes & Yes & Yes & Yes \\
Country FE & Yes & Yes & Yes & Yes \\
\hline Adj. R-sq. & 0.025 & 0.124 & 0.168 & 0.120 \\
Observations & 39097 & 60966 & 58499 & 20043 \\
DHS Clusters & 6508 & 6720 & 6725 & 6012 \\
Ethnicities & 306 & 308 & 308 & 306 \\
Sample & Full & Full & Full & Full \\
& Age 15-20 & Age 20-29 & Age 30-44 & Over Age 44 \\
\hline
\end{tabular}

Note: OLS Estimates. HIV is a dummy variable for testing positive to HIV. Slave Trade is the natural log of 0.01 plus transatlantic slave exports normalized by ethnic land area. Clustered robust standard errors at a DHS cluster level in parentheses. Clustered robust standard errors at an ethnicity level in square brackets. The controls include: Regional GDP 2000, Population Density 2000, Population Density 1800, Rugged Terrain, Mean Elevation, Water Basins, Rainfall, Temperature, Soil PH, Soil Nutrients Availability, Growing Season, Colonial Routes, Colonial Railways, Christian Missions, Year of the Survey, Sex, Marital Status, Education, Religion, Employment, Wealth, Relationship to the Head, Age of the Household Head, Sex of the Household Head, and Number of Household Members. 
Table A14: HIV and the Slave Trade by Age Cohort and Gender

\begin{tabular}{|c|c|c|c|c|}
\hline & \multicolumn{4}{|c|}{ HIV } \\
\hline & \multicolumn{4}{|c|}{ Panel A - Women } \\
\hline & (1) & $(2)$ & $(3)$ & (4) \\
\hline \multirow[t]{3}{*}{ Slave Trade } & 0.00241 & 0.00394 & 0.00482 & 0.00199 \\
\hline & $(0.00129)$ & $(0.00156)$ & $(0.00211)$ & $(0.00351)$ \\
\hline & {$[0.00127]$} & {$[0.00244]$} & {$[0.00441]$} & {$[0.00377]$} \\
\hline Controls & Yes & Yes & Yes & Yes \\
\hline Country FE & Yes & Yes & Yes & Yes \\
\hline Adj. R-sq. & 0.037 & 0.149 & 0.177 & 0.133 \\
\hline Observations & 20878 & 35203 & 32293 & 7230 \\
\hline DHS Clusters & 6010 & 6623 & 6614 & 4154 \\
\hline Ethnicities & 304 & 308 & 308 & 290 \\
\hline \multirow[t]{4}{*}{ Sample } & Women & Women & Women & Women \\
\hline & Age $15-20$ & Age 20-29 & Age $30-44$ & Over Age 44 \\
\hline & \multicolumn{4}{|c|}{ Panel B - Men } \\
\hline & $(1)$ & $(2)$ & $(3)$ & $(4)$ \\
\hline Slave Trade & -0.000131 & 0.000110 & 0.00160 & 0.00496 \\
\hline & $(0.000805)$ & $(0.00121)$ & $(0.00175)$ & $(0.00260)$ \\
\hline & {$[0.000641]$} & {$[0.00163]$} & {$[0.00304]$} & {$[0.00387]$} \\
\hline Controls & Yes & Yes & Yes & Yes \\
\hline Country FE & Yes & Yes & Yes & Yes \\
\hline Adj. R-sq. & 0.015 & 0.068 & 0.159 & 0.115 \\
\hline Observations & 18219 & 25763 & 26206 & 12813 \\
\hline DHS Clusters & 5723 & 6280 & 6432 & 5369 \\
\hline Ethnicities & 304 & 306 & 307 & 302 \\
\hline Sample & Men & Men & Men & Men \\
\hline & Age $15-20$ & Age 20-29 & Age $30-44$ & Over Age 44 \\
\hline
\end{tabular}

Note: OLS Estimates. HIV is a dummy variable for testing positive to HIV. Slave Trade is the natural log of 0.01 plus transatlantic slave exports normalized by ethnic land area. Clustered robust standard errors at a DHS cluster level in parentheses. Clustered robust standard errors at an ethnicity level in square brackets. The controls include: Regional GDP 2000, Population Density 2000, Population Density 1800, Rugged Terrain, Mean Elevation, Water Basins, Rainfall, Temperature, Soil PH, Soil Nutrients Availability, Growing Season, Colonial Routes, Colonial Railways, Christian Missions, Year of the Survey, Marital Status, Education, Religion, Employment, Wealth, Relationship to the Head, Age of the Household Head, Sex of the Household Head, and Number of Household Members. 
Table A15: HIV and the Slave Trade by Marital Status - 2SLS Estimates

\begin{tabular}{lcccccc}
\hline & & \multicolumn{5}{c}{ Second Stage: HIV } \\
& $(1)$ & $(2)$ & $(3)$ & $(4)$ & $(5)$ & $(6)$ \\
\hline Slave Trade & 0.00553 & -0.00569 & 0.00721 & 0.00326 & -0.00363 & -0.00636 \\
& $(0.00285)$ & $(0.00202)$ & $(0.00339)$ & $(0.00334)$ & $(0.00320)$ & $(0.00249)$ \\
& {$[0.00571]$} & {$[0.00336]$} & {$[0.00615]$} & {$[0.00587]$} & {$[0.00388]$} & {$[0.00335]$} \\
Controls & Yes & Yes & Yes & Yes & Yes & Yes \\
Country FE & Yes & Yes & Yes & Yes & Yes & Yes \\
\hline Adj. R-sq. & 0.000 & -0.001 & -0.000 & 0.000 & -0.001 & -0.001 \\
Observations & 103396 & 63524 & 58606 & 44790 & 28147 & 35377 \\
DHS Clusters & 6749 & 6633 & 6731 & 6684 & 5991 & 6398 \\
Ethnicities & 308 & 307 & 308 & 308 & 301 & 306 \\
Sample & Married & Unmarried & Married & Married & Unmarried & Unmarried \\
& & & Women & Men & Women & Men \\
\hline \hline & & & First Stage: Slave Trade & & \\
\hline Distance from Coast & -0.748 & -0.819 & -0.740 & -0.759 & -0.826 & -0.816 \\
& $(0.0418)$ & $(0.0502)$ & $(0.0427)$ & $(0.0419)$ & $(0.0544)$ & $(0.0511)$ \\
& {$[0.186]$} & {$[0.185]$} & {$[0.186]$} & {$[0.186]$} & {$[0.179]$} & {$[0.192]$} \\
\hline First St. F Stat. DHS Cl. & 319.26 & 267.77 & 299.66 & 328.91 & 230.35 & 254.36 \\
First St. F Stat. Ethnic Cl. & 16.19 & 19.50 & 15.75 & 16.70 & 21.33 & 18.13 \\
Anderson LR Stat. & 9510.55 & 7155.86 & 5142.81 & 4365.90 & 3218.64 & 3924.80 \\
Cragg Donald F Stat. & 9961.67 & 7574.35 & 5375.11 & 4585.66 & 3409.76 & 4150.67 \\
Stock and Yogo Crit. Val. & 16.38 & 16.38 & 16.38 & 16.38 & 16.38 & 16.38 \\
\hline
\end{tabular}

Note: 2SLS Estimates. HIV is a dummy variable for testing positive to HIV. Slave Trade is the natural log of 0.01 plus transatlantic slave exports normalized by ethnic land area. Distance from Coast is the centroid distance of a DHS cluster from the coast. Clustered robust standard errors at a DHS cluster level in parentheses. Clustered robust standard errors at an ethnicity level in square brackets. The controls include: Regional GDP 2000, Population Density 2000, Population Density 1800, Rugged Terrain, Mean Elevation, Water Basins, Rainfall, Temperature, Soil PH, Soil Nutrients Availability, Growing Season, Colonial Routes, Colonial Railways, Christian Missions, Year of the Survey, Age, Sex, Education, Religion, Employment, Wealth, Relationship to the Head, Age of the Household Head, Sex of the Household Head, and Number of Household Members. Sex is dropped from Models 3-6. 
Table A16: HIV and the Slave Trade by Co-residence - 2SLS Estimates

\begin{tabular}{|c|c|c|c|c|}
\hline & \multicolumn{4}{|c|}{ Second Stage: HIV } \\
\hline & $(1)$ & $(2)$ & $(3)$ & (4) \\
\hline \multirow[t]{3}{*}{ Slave Trade } & 0.0128 & 0.00435 & -0.0212 & 0.0145 \\
\hline & $(0.00926)$ & $(0.00353)$ & $(0.0240)$ & $(0.00587)$ \\
\hline & {$[0.0106]$} & {$[0.00589]$} & {$[0.0267]$} & {$[0.00847]$} \\
\hline Controls & Yes & Yes & Yes & Yes \\
\hline Country FE & Yes & Yes & Yes & Yes \\
\hline Adj. R-sq. & -0.000 & 0.000 & -0.006 & -0.002 \\
\hline Observations & 8858 & 48510 & 3768 & 37936 \\
\hline DHS Clusters & 4125 & 6678 & 2284 & 6316 \\
\hline Ethnicities & 285 & 308 & 211 & 256 \\
\hline \multirow[t]{4}{*}{ Sample } & Married & Married & Married & Married \\
\hline & Women & Women & Men & Men \\
\hline & No Co-res. & Co-res. & No Co-res. & Co-res. \\
\hline & \multicolumn{4}{|c|}{ First Stage: Slave Trade } \\
\hline \multirow[t]{3}{*}{ Distance from Coast } & -0.813 & -0.728 & -0.585 & -0.576 \\
\hline & $(0.0687)$ & $(0.0429)$ & $(0.0758)$ & $(0.0410)$ \\
\hline & {$[0.187]$} & {$[0.188]$} & {$[0.217]$} & {$[0-231]$} \\
\hline First St. F Stat. DHS Cl. & 140.14 & 287.17 & 59.58 & 197.41 \\
\hline First St. F Stat. Ethnic Cl. & 18.81 & 14.96 & 7.27 & 6.25 \\
\hline Anderson LR Stat. & 979.31 & 4104.14 & 145.48 & 1749.97 \\
\hline Cragg Donald F Stat. & 1035.38 & 4282.88 & 148.29 & 1790.91 \\
\hline Stock and Yogo Crit. Val. & 16.38 & 16.38 & 16.38 & 16.38 \\
\hline
\end{tabular}

Note: 2SLS Estimates. HIV is a dummy variable for testing positive to HIV. Slave Trade is the natural log of 0.01 plus transatlantic slave exports normalized by ethnic land area. Distance from Coast is the centroid distance of a DHS cluster from the coast. Clustered robust standard errors at a DHS cluster level in parentheses. Clustered robust standard errors at an ethnicity level in square brackets. The controls include: Regional GDP 2000, Population Density 2000, Population Density 1800, Rugged Terrain, Mean Elevation, Water Basins, Rainfall, Temperature, Soil PH, Soil Nutrients Availability, Growing Season, Colonial Routes, Colonial Railways, Christian Missions, Year of the Survey, Age, Education, Religion, Employment, Wealth, Relationship to the Head, Age of the Household Head, Sex of the Household Head, and Number of Household Members. 
Table A17: Norms of Premarital Sexual Behavior for Girls and the Slave Trade - Spatial Clustering

\begin{tabular}{lcccccc}
\hline & $(1)$ & $(2)$ & $(3)$ & $(4)$ & $(5)$ & $(6)$ \\
& Allowed & Early Marriage & Free & Virginity & Weakly Censored & Prohibited \\
\hline Slave Trade & 0.00900 & -0.00387 & -0.00448 & -0.00503 & 0.00703 & -0.00265 \\
& $(0.00642)$ & $(0.0132)$ & $(0.0313)$ & $(0.0169)$ & $(0.0176)$ & $(0.00897)$ \\
Controls & No & No & No & No & No & No \\
Country FE & Yes & Yes & Yes & Yes & Yes & Yes \\
\hline Adj. R-sq. & -0.008 & -0.012 & -0.012 & -0.012 & -0.011 & -0.012 \\
Observations & 83 & 83 & 83 & 83 & 83 & 83 \\
\hline
\end{tabular}

Note: OLS estimates. Slave Trade is the natural log of 0.01 plus transatlantic slave exports normalized by ethnic land area. Conley (1999) standard errors in parentheses, constructed assuming a window with weights equal to one for observations less than $200 \mathrm{~km}$ apart, and zero for observations further apart.

Table A18: Mode of Marriage and the Slave Trade - Spatial Clustering

\begin{tabular}{lccccc}
\hline & $(1)$ & $(2)$ & $(3)$ & $(4)$ & $(5)$ \\
& No Consideration & Bride Price & Bride Service & Female Exchange & Token Bride \\
\hline Slave Trade & 0.000912 & -0.0117 & 0.0171 & -0.00927 & 0.00302 \\
& $(0.00184)$ & $(0.0138)$ & $(0.0115)$ & $(0.00567)$ & $(0.00903)$ \\
\hline Controls & No & No & No & No & No \\
Country FE & Yes & Yes & Yes & Yes & Yes \\
\hline Adj. R-sq. & -0.005 & -0.002 & 0.008 & 0.005 & -0.004 \\
Observations & 208 & 208 & 208 & 208 & 208 \\
\hline
\end{tabular}

Note: OLS estimates. Slave Trade is the natural log of 0.01 plus transatlantic slave exports normalized by ethnic land area.Conley (1999) standard errors in parentheses, constructed assuming a window with weights equal to one for observations less than $200 \mathrm{~km}$ apart, and zero for observations further apart. 